This item was submitted to Loughborough's Research Repository by the author.

Items in Figshare are protected by copyright, with all rights reserved, unless otherwise indicated.

\title{
Validation of a cyclic plasticity computational method using fatigue full-field deformation measurements
}

PLEASE CITE THE PUBLISHED VERSION

http://dx.doi.org/10.1111/ffe.12396

PUBLISHER

(c) Wiley

VERSION

AM (Accepted Manuscript)

\section{PUBLISHER STATEMENT}

This work is made available according to the conditions of the Creative Commons Attribution-NonCommercialNoDerivatives 4.0 International (CC BY-NC-ND 4.0) licence. Full details of this licence are available at: https://creativecommons.org/licenses/by-nc-nd/4.0/

\section{LICENCE}

CC BY-NC-ND 4.0

\section{REPOSITORY RECORD}

Cuadra, J., Konstantinos Baxevanakis, A. Loghin, and A. Kontsos. 2016. "Validation of a Cyclic Plasticity Computational Method Using Fatigue Full-field Deformation Measurements". Loughborough University. https://hdl.handle.net/2134/25784. 


\title{
Validation of a Cyclic Plasticity Computational Method Using
}

\section{Fatigue Full Field Deformation Measurements}

\author{
Jefferson Cuadra ${ }^{1}$,Konstantinos P. Baxevanakis ${ }^{2}$, Adrian Loghin ${ }^{3}$, and Antonios Kontsos, ${ }^{2}{ }^{*}$ \\ ${ }^{1}$ Nondestructive Characterization Institute, Lawrence Livermore National Laboratory, P.O. Box 808 L-229, \\ Livermore, CA 94551 \\ 2 Theoretical $\&$ Applied Mechanics Group, Mechanical Engineering 6 Mechanics Department, \\ Drexel University, Philadelphia, PA \\ ${ }^{3}$ Lifing Lab, Structural Materials Lab, General Electric - GRC, Niskayuna, NY
}

\begin{abstract}
The evolution of crack tip displacement and strain fields during uniaxial, room temperature, low cycle fatigue experiments of Nickel superalloy compact tension specimens were measured by a digital image correlation approach and were further used to validate a cyclic plasticity model and corresponding deformation calculations made by a finite elements methodology. The experimental results provided data trends for the opening displacements and near crack tip strains as function of cycles. The calculated full field deformation data were then used to validate the corresponding results obtained by a confined crack tip plasticity model which was calibrated using stressstrain measurements on round-bar specimens. This type of direct comparison demonstrated that the computational model was capable to adequately capture the crack opening displacements at various stages of the specimen's fatigue life, providing in this way a tool for quantitative cyclic plasticity model validation. In addition, this integrated experimental-computational approach provides a framework to accelerate our understanding related to interactions of fatigue test data and models, as well as ways to inform one another.
\end{abstract}

Keywords: Digital Image Correlation, Cyclic Plasticity, Fatigue Crack Growth, Validation 


\section{Introduction}

The topic of fatigue crack growth characterization, quantification and modeling has been active in the field of mechanics for several decades. By evaluating crack initiation and growth, it is possible for example to predict the degradation of machinery components due to stress corrosion and fatigue ${ }^{1}$ In the case of metals subjected to cyclic loads, microstructure-specific 'short' cracks eventually nucleate near persistent slip bands, at grain-scale plastic strain/stress localization sites, e.g. grain boundaries, or near coarse particles, inclusions and porosities. Further cyclic loading is possible to lead to the formation of one or more 'long' cracks the growth of which ultimately leads to failure ${ }^{3}$. Several related investigations have focused on the fatigue limit, number of cycles to failure, mean stress/strain evolution and effects of applied loading on hysteresis loops ${ }^{4-6}$. Ex situ microscopy was implemented in some ${ }^{7-10}$, and in situ in others ${ }^{11}$ to observe microstructure related phenomena. Furthermore, contributions in examining the evolution of the fatigue process have been provided by nondestructive evaluation including neutron diffraction ${ }^{12-14}$, high energy X-rays ${ }^{15}$, Acoustic Emis$\operatorname{sion}^{16-18}$ and Digital Image Correlation (DIC $)^{19,}{ }^{20}$. In addition, several recent experimental approaches have reported the use of in situ loading devices, allowing high magnification imaging of miniaturized specimens in both room and high temperature conditions ${ }^{21,22}$.

In this context, strain mapping at various length scales and its relationship to both microstructural features and mechanical behavior has been greatly advanced over the past years through the use of optical, non-contact full field measurement techniques, capable of measuring 2D and 3D surface deformations ${ }^{23-30}$. In DIC, the object is typically viewed by a pair of high resolution digital CCD 
cameras. The 3D image correlation stems from the combination of two-camera image correlation and photogrammetry. A random or regular pattern with good contrast is applied to the surface of the test object, which is monitored continuously as it deforms, while surface correlation areas known as facets or subsets (typically 5-20 pixels squared) are tracked with sub-pixel accuracy. DIC has been used to a wide range of applications and material systems $\mathrm{s}^{31-34}$ to validate damage related phenomena, as well as to offer experimental information in order to calibrate and/or validate computational models. Related to fatigue crack growth on metals, there is an increasing activity reported in the literature in the past few years. For example, El Bartali et al. implemented an in situ approach to obtain quantitative values of the fatigue surface damage in a two-phased alloy ${ }^{35}$. Using this technique the authors monitored the evolution of damage micromechanisms and identified that microcrack initiation occurs at ferrite grain boundaries. Hamam et al. analyzed fatigue crack displacement fields in steel and estimated the associated elastic fields through an integrated approach ${ }^{36}$. Carroll et al. correlated two full field DIC methods with microscale analysis offering a multiscale approach to study fatigue crack growth in titanium ${ }^{37}$. Later, they combined high resolution DIC data with electron backscatter diffraction (EBSD) measurements to quantify the accumulated plastic strain fields associated with the propagation of a fatigue crack in a Ni-based superalloy ${ }^{38}$. Abuzaid et al. employed high resolution DIC to correlate early localizations of plastic strains during loading with the appearance of micro-cracks on polycrystalline Hastelloy $\mathrm{X}^{39}$ specimens. Vanlanduit et al. proposed a post-processing algorithm for the identification of the crack length and the stress intensity factor as a function of fatigue $\operatorname{cycles}^{28}$. Finally, Mathieu et al. conducted fatigue experiments on titanium samples and developed crack propagation laws based on DIC data ${ }^{40,41}$. 
On the other hand, modeling crack growth under fatigue loading has been a challenging computational mechanics topic. In the general case, the problem is nonlinear (elasto-plastic) with reversed plasticity complicated by crack closure and branching effects. Therefore, intensive computational work with specific emphasis on mesh sensitivity and convergence issues has been reported. Difficulties encountered in the modeling of fatigue problems are discussed, for example, by McClung \& Sehitoglu ${ }^{42,43}$. Typically, crack growth schemes consist of releasing nodes ahead of the crack tip. However, the way node(s) "release" and the assumed crack tip "advances" varies in the literature ${ }^{44}$. Most of the proposed models use standard finite elements based on stress intensity defined crack propagation laws ${ }^{1,45,46}$. For example, Nguyen et al. imposed a cohesive law to model fatigue crack growth achieving steady crack growth ${ }^{45}$. Other approaches are based on the extended finite element method $^{47,48}$. Another class of computational fatigue investigations are those that combine some experimental technique (e.g. DIC) with a modeling method to enhance the latter with some physical information. Such studies could be further separated in two groups: a) those ${ }^{49}$ that DIC is used to offer inputs that calibrate the model by extracting experimental information e.g. critical displacement or plastic strain, and b) those ${ }^{20,31,50,51}$ that use DIC to evaluate a numerical approach by comparison of some outputs e.g. displacement/strain fields in relation to stress intensity factors and crack size. Focusing on fatigue applications on metals, there is a limited number of investigations relying on DIC measurements used to validate computational methods ${ }^{52,53}$ that include both a cyclic plasticity law formulation and its numerical implementation.

In this article, an integrated experimental and computational approach is presented for Nickel superalloy compact tension specimens under fatigue loading. Experimental information obtained by 
post-processing full field DIC data was used to validate a confined crack tip plasticity computational model. The constitutive law used in the computational model was defined by using previously obtained data of uniaxial tests on round specimens. The results presented herein demonstrate that the integrated approach requires limited computational resources and provides satisfactory comparative results for the near crack tip plasticity and its evolution as a function of fatigue life. It should be noted that the current investigation was conducted using US customary units and therefore all graphs and tables were prepared under this convention. However, to enable the reader to follow our study, SI units followed by their US equivalent in parentheses are used throughout the manuscript.

\section{Methodology}

\subsection{Experimental setup}

In the experimental portion of this study, compact tension samples were machined, as shown in Fig. 1a, with dimensions following ASTM E1820. The material was a Nickel superalloy with yield strength of $1213 \mathrm{MPa}(176 \mathrm{ksi})$ at $0.2 \%$ offset, Young's Modulus of $219.9 \mathrm{GPa}$ (31.9 Msi), Poisson's ratio of 0.3 and density of $27,680 \mathrm{~kg} / \mathrm{m}^{3}\left(14.15 \mathrm{lb} / \mathrm{in}^{3}\right)^{54}$. Prior to fatigue crack experiments, a similar setup was used in accordance to ASTM E1820 to grow pre-cracks of approximately 60 mils (1.52 $\mathrm{mm}$ ), which were monitored using the DIC system with a field of view (FOV) of $10 \mathrm{~mm} \times 8 \mathrm{~mm}$ (393.70 mils x 314.96 mils).

The fatigue parameters utilized included a frequency of $10 \mathrm{~Hz}$, an $R$-value of 0.05 and a maximum load of $3.59 \mathrm{kN}$ (808 lbf) calculated based on a stress intensity factor of $16.48 \mathrm{MPa} \cdot \mathrm{m}^{1 / 2}(15$ $\left.\mathrm{ksi} \cdot \mathrm{in}^{1 / 2}\right)$. Subsequently, the specimens were tested at a speed of $0.33 \mathrm{~Hz}$ and the same $R$-value as the pre-crack test but the maximum load was calculated based on initial stress intensity factor. The 
stress intensity factor range, $\Delta K$, for the first sample reported in this article was equal to 21.98 $\mathrm{MPa} \cdot \mathrm{m}^{1 / 2}\left(20 \mathrm{ksi} \cdot \mathrm{in}^{1 / 2}\right)$ over a period of 6,500 cycles and $32.97 \mathrm{MPa} \cdot \mathrm{m}^{1 / 2}\left(30 \mathrm{ksi} \cdot \mathrm{in}^{1 / 2}\right)$ over 17,858 cycles for a total of 24,358 cycles resulting in a crack growth of approximately $4.70 \mathrm{~mm}$ (185 mils), while the second sample was fatigued for 6,000 cycles under a stress intensity factor range of 49.45 $\mathrm{MPa} \cdot \mathrm{m}^{1 / 2}\left(45 \mathrm{ksi} \cdot \mathrm{in}^{1 / 2}\right)$, which produced a final crack length of $4.37 \mathrm{~mm}(172 \mathrm{mils})$.

In order to monitor the crack growth and associated surrounding displacement and strain fields, the setup included a DIC system from GOM ARAMIS 3D (shown in the dashed line box in Fig. 1b) that consisted of a 5-megapixel stereo camera system with a peak acquisition of 30 frames per second. The two specimens were analyzed at the same exposure time of $36 \mathrm{~ms}$ and at two different FOV which were calibrated for $50 \mathrm{~mm}$ (1.97 in) lenses by adjusting the working distance, camerato-camera distance and angle, while the lighting conditions were selected using recommended settings provided by the manufacturer. Sample one was adjusted to a $485 \mathrm{~mm}$ (19.09 in) working distance with $176 \mathrm{~mm}$ (6.93 in) camera separation which resulted in a camera angle of $26.2^{\circ}$ after calibrating for a FOV of $65 \mathrm{~mm} \times 55 \mathrm{~mm}$ (2.56 in x $2.17 \mathrm{in}$ ). In the case of sample two, the FOV was reduced to $25 \mathrm{~mm} \times 21 \mathrm{~mm}$ (984.25 mils x 826.77 mils) which corresponded to a working distance of $250 \mathrm{~mm}$ (9.84 in) and a camera separation distance of $74 \mathrm{~mm}$ (2.91 mils). The calibration process for both setups consisted of a few images of a calibration block for at least 13 different positions relative to the cameras under acceptable focus and lighting. A speckle pattern was spray painted on the sample (shown in Fig. 1d) to create a contrast on the images for tracking and measuring purposes while the sample was mechanically loaded. Prior testing, the sensitivity of the setup was measured resulting in $\pm 4 \mu \mathrm{m}(0.16 \mathrm{mils})$ for displacement and $\pm 400 \mu \mathrm{m} / \mathrm{m}(15.75$ 
mils/39.37 in) for strain for both samples and a resolution of $22 \mu \mathrm{m} /$ pixel $(0.87$ mils/pixel $)$ for sample one and $13 \mu \mathrm{m} /$ pixel (0.051 mils/pixel) for sample two. The two samples utilized a facet size (i.e. subset size) of 19 pixels and a step size of 12 pixel. The mechanical and optical systems were interconnected via analog to digital inputs to allow recording of the load range and directly relate this with specific images, as well as to permit inputs of the customized image acquisition process since images were acquired only at peak load values based on an in-house script that searches for load and cycle number to enable recording of DIC data. This acquisition algorithm recorded images for the first 100 cycles and then it recorded one image for every 100 fatigue cycles.

The DIC related images recorded from both samples had sufficient resolution to allow the extraction of displacement and strain values close to the crack tip. Such analyses were performed by using multiple point line profiles and/or two-point measurements (virtual gages) which were then compared to the results obtained by the computational model (discussed in the following section). The way these two-point gages were defined is shown in Fig. 1c and Fig. 1d and the representative details for their length and distance from the machined notch for sample two are reported in Table 1. It is important to note that the gages were not horizontally aligned since they were selected post mortem following the actual crack growth path on the surface.

\subsection{Cyclic plasticity constitutive model description and calibration}

Material testing and constitutive model calibration were carried out similar to the development described by Ismonov et al.55. To calibrate the constitutive model, round bar specimens were tested to capture post yield response at different strain ranges. The entire procedure is described in detail 
by Ismonov et al., however, the main steps are described also herein for completeness. The round bar specimens were machined from a rolled alloy billet. In order to calibrate a confined crack tip plasticity (CCTP) model, a constitutive law capable to capture cyclic stress-strain behavior was used. Specifically, the material model adopted is a rate-independent version of the nonlinear kinematic hardening model developed by Chaboche ${ }^{56,57}$. The constitutive equations are based on linear isotropic elasticity, a von Mises yield function and the associated flow rule. This model can be used to simulate the monotonic hardening and the Bauschinger effect and allows the superposition of several kinematic models or isotropic hardening models. Details related to the model implementation are provided in ANSYS documentation ${ }^{58}$.

The yield function in the Chaboche non-linear kinematic hardening model implemented in ANSYS is defined as

$$
F=\left[\frac{3}{2}\left(\boldsymbol{\sigma}^{\prime}-\boldsymbol{\beta}\right):\left(\boldsymbol{\sigma}^{\prime}-\boldsymbol{\beta}\right)\right]^{1 / 2}-R=0
$$

where $\boldsymbol{\sigma}^{\prime}$ is the deviatoric stress tensor, $\boldsymbol{\beta}$ is the back-stress tensor that translates the yield surface during plastic deformation and $R$ is the isotropic hardening variable. The back stress tensor is defined as a superposition of $n$ kinematic hardening models

$$
\boldsymbol{\beta}=\sum_{i=1}^{n} \boldsymbol{\beta}_{i}
$$

Then, the evolution of the back-stress for each kinematic hardening model is given by

$$
\Delta \boldsymbol{\beta}_{i}=\frac{2}{3} C_{i} \Delta \boldsymbol{\varepsilon}^{p l}-\gamma_{i} \boldsymbol{\beta}_{i} \Delta \bar{\varepsilon}^{p l}
$$


where $C_{i}$ and $\gamma_{i}(i=1,2, \ldots, n)$ are material parameters describing the kinematic hardening behavior, $\Delta \boldsymbol{\varepsilon}^{p l}$ is the plastic strain increment tensor and $\Delta \bar{\varepsilon}^{p l}$ is the equivalent plastic strain increment.

Accordingly, the isotropic hardening behavior is captured by the following equation

$$
R=\sigma_{y}+R_{0} \bar{\varepsilon}^{p l}+R_{\infty}\left(1-e^{-b \bar{\varepsilon}^{p l}}\right)
$$

where $\sigma_{y}$ is the initial yield strength, $R_{0}, R_{\infty}, b$ are material parameters that characterize the isotropic hardening behavior and $\bar{\varepsilon}^{p l}$ is the accumulated equivalent plastic strain.

The material parameters for the Ni-based superalloy were calibrated using the PEZ optimization software (internal design tool of GE used for computer simulation design studies related to probabilistic design and optimization) and are listed in Table 2. In Fig. 2, a comparison between experimental data and the constitutive model response is presented for an applied total strain ratio $R_{\varepsilon}=\varepsilon_{\min } / \varepsilon_{\max }=-1$. Overall, the model prediction is satisfying although it is underestimating the plastic strain ranges.

\subsection{Computational approach}

A half longitudinal symmetry model was used as shown in Fig. 3. The geometry (Parasolid format) is used to insert an edge crack at the tip of the machined notch and the resultant geometry is meshed afterwards for the following finite element analysis. All pre-processing with meshes containing cracks of different sizes were carried out in 3DFAS (GE proprietary tool ${ }^{59}$ ) using MeshSim 
capabilities from Simmetrix, $\operatorname{Inc}^{60}$. A typical mesh contains about 125,000 nodes and 70,000 elements. All elements used were quadratic and the simulations were run in ANSYS ${ }^{\mathrm{TM}}$. Fig. 3a shows the overall geometry and the mesh of the model containing a $1.73 \mathrm{~mm}$ (68 mils) crack along with close-up of the mesh along the crack front containing 10 wedge-brick element layers. The boundary conditions enforce the symmetry, the constraint along the loading direction in the pin hole and the rigid body motion as described in Fig. 3b and Fig. 3c. The loading is applied to the opposite pinhole. The loading mission considers a cycle from zero to the maximum applied load and eventual contact between the crack faces is captured using contact elements. It should be further noted that the crack is considered to be stationary (i.e. there is no crack growth).

Further, a mesh sensitivity study was conducted to verify that the relative crack face displacements and the strain gradient ahead of the crack converge with respect to increased mesh refinement. A description of the mesh control parameters as well as the location of paths along which the strain gradient was extracted from are provided in Fig. 4a. The mesh at the crack tip uses one angular layer of wedge elements followed by several radial layers of brick elements and the rest of the volume is meshed using tetrahedrons. The compatibility between hexahedron elements and the free tetrahedron mesh is provided by pyramid elements. The number of elements along the crack front, radius of the brick layers, number of wedge elements at the crack tip, mesh size on the crack surfaces are fully controlled by the user ${ }^{59}$ and all elements are of quadratic type. Four different models were used for a crack length of $4.37 \mathrm{~mm}$ (172 mils) where only the mesh at the tip and along the crack surface was modified since we are interested in strain gradient in front of the crack and displacement along the crack faces. Mesh \#1 (less refined) consisted of a crack face mesh size equal to $0.51 \mathrm{~mm}$ (20 
mils), a crack tip mesh size of $66.04 \mu \mathrm{m}$ (2.6 mils) and a tunnel radius element size of $63.50 \mu \mathrm{m}$ (2.5 mils). In Mesh \#2, the crack face mesh size was refined to $0.25 \mathrm{~mm}$ (10 mils) and all other parameters remained the same. Mesh \#3 was further discretized with the crack tip mesh size being equal to $33.02 \mu \mathrm{m}$ (1.3 mils) and the tunnel radius element size equal to $25.40 \mu \mathrm{m}$ (1 mil). Finally, in Mesh \#4 (more refined), the crack face mesh size was decreased to $0.13 \mathrm{~mm}$ (5 mils). In all cases, 12 wedge elements were used. The results of the four simulations are post-processed in a similar manner as described in Section 3.3. As it can be observed in Fig. 4b, all four meshes provide very similar results for the relative displacement $\Delta u_{y}=u_{y}^{\text {top }}-u_{y}^{b o t}$ and strain quantities $\left(\varepsilon_{y y}\right)$ indicating solution convergence.

\section{Results and discussion}

\subsection{Experimental results}

The fatigue crack size was verified by acquiring various images at different magnifications using an Olympus BH-2 optical microscope. Fig. 5 shows the front and back view of sample one in addition to its corresponding microscope images at 50x magnification around the machined notch. The optical images are a cropped view showing a $1.32 \mathrm{~mm}$ (52 mils) long crack compared to the total crack length of $4.70 \mathrm{~mm}$ (185 mils). Such optical images confirmed the crack size obtained by the DIC system. Moreover, the microscope images also showed that the crack tunneled symmetrically through the thickness of the sample and in a relatively horizontal manner. A similar qualitative study was performed for sample two to verify the crack characteristics. In addition, both samples were evaluated quantitatively using the DIC displacement and strain fields around the crack. Fig. 
6 provides the full-field displacement contours in addition to displacement profiles behind and ahead of the crack tip which could be potentially comparable to the computational model. The full-field displacement contour as a function of cycles clearly shows the fatigue crack growth as the gradient widens with increasing crack length. The contours also show that, even though, the load is increased after 6,500 cycles (i.e. by increasing the stress intensity range from $21.98 \mathrm{MPa} \cdot \mathrm{m}^{1 / 2}$ to 32.97 $\mathrm{MPa} \cdot \mathrm{m}^{1 / 2}\left(20\right.$ to $\left.\left.30 \mathrm{ksi} \cdot \mathrm{in}^{1 / 2}\right)\right)$ the displacements increase only slightly up to 10,000 cycles.

This trend is depicted more evidently by plotting the line profiles ahead and behind the crack tip illustrated in Fig. 6b and Fig. 6c, respectively. In Fig. 6b, the path lines are at a distance ahead of the crack tip compared to those in Fig. 6c in which the two path lines are behind the crack tip. Moreover, the top and bottom arrays, shown Fig. 6a and plotted in Fig. 6c, are far from the plastic zone. These displacement data arrays capture similar deformation results to that of an elastic analysis depending on the distance from the crack tip and DIC gage length. However, by decreasing the FOV, thus increasing the resolution in sample two, narrower path lines, which were closer to the crack tip, were achieved and extracted for comparison to the model (shown in Fig. 12). Both these types of DIC data extraction characterize the displacement close and far to the crack tip as function of cycles. Notice that by having these results, the rate of displacement can be calculated as a function of increasing cycles. Furthermore, it is clearly seen that regardless of the load increase the displacements are steadily increasing on average at a rate of $0.127 \mu \mathrm{m} /$ cycle $(0.005 \mathrm{mils} / \mathrm{cycle})$ near the crack tip. This fact suggests that the displacements are increasing relatively in linear trend with respect to number of cycles. In the case of the values behind the crack tip, a similar behavior is observed even for the displacements further away of the machined notch, i.e. for the bottom array. 
The same type of analysis was implemented to sample two in addition to using a two-point gage at the machined notch to confirm this linear trend in the displacements and to analyze the effects of applying a higher load and stress intensity range.

An additional parameter, which could potentially provide more insightful information about the fatigue crack growth, is the calculated strains from the measured displacements. Fig. 7a shows the full-field maps of the strain with increasing number of cycles. The full-field contour plots with a fixed legend provide additional information and a method to track the crack tip by identifying gradient in the displacement. It can be observed that the area gradient in the displacement, shown previously, reveals a plastic wake around the crack faces. This high strain concentration is partially a calculation artifact since there is a discontinuity present and its magnitude varies depending on the facet and step size. By extracting a strain point value around the machined notch, the strain evolution of the plastic wake can be analyzed, as shown in Fig. 7b. The evolution of strain depicts an evident change in rate after 10,000 cycles by increasing the stress intensity range.

Correspondingly, the strain line profile ahead of the machined notch was extracted to evaluate its spatial distribution around the plastic wake. Fig. 7c portrays the shift of this high concentration area from $3.56 \mathrm{~mm}$ to $5.08 \mathrm{~mm}$ ( 0.14 inches to 0.20 inches) with strain values that go from $1.2 \%$ to $3.7 \%$ over the period of 24,358 cycles. This exponentially increasing strain also depicts that for higher cycles the strain plateaus near the machined notch. Such behavior could be associated to the discontinuity imposed by the crack. By using both DIC measured displacement and strain fields, the crack was located and tracked which allowed to remove part of the computational artifacts 
that caused high strain values. Fig. 8a shows the shifted line profiles ahead of the crack tip of the strain for sample one. It can be seen that the new line profiles only increase from $0.12 \%$ to $0.375 \%$ with the same nonlinear increase near the crack tip. In the case of Fig. 8b, the strain contours (i.e. in the loading direction, Y global coordinate system direction) without any post-processing filter show clearly the location of the crack tip and the surrounding plastic wake. It can also be seen that the maximum strain values (see in the color bars) increase from $0.25 \%$ to $0.38 \%$ following the same trend as the results in the extracted profile lines. Although this was a refined evaluation of the strains, the results still depend on facet and step size due to the fact that this is a calculated parameter. In addition, the strain values near the crack tip are not as reliable since these are associated to the singularity associated with the discontinuity in the field. Therefore, the values used herein to compare the computational to experimental results are two-point measurements near the crack tip instead of single points.

\subsection{Modeling results}

The computational model described in Sections 2.2 and 2.3 was employed to analyze the two specimens at various stages or their fatigue life. Following the experimental data for the second sample that indicates a crack of $4.37 \mathrm{~mm}$ (172 mils) after 6,000 cycles and an applied maximum loading of $9.79 \mathrm{kN}(2,200 \mathrm{lbf})$, a finite element model was prepared to represent these conditions. In Fig. 9, representative plots for the displacement field $u_{y}$, the total strain $\varepsilon_{y y}$ and stress $\sigma_{y y}$ at maximum load at 1000 cycles are presented. A crack size of $1.85 \mathrm{~mm}$ (73 mils) was identified at this stage from the DIC data and implemented to the finite element model. The displacement field shows the 
expected uniformity along the $y$ axis. The solution is smooth around the crack tip, the notch and the pins, which shows that the mesh is well refined around these high stress concentration areas.

The normal strain component $\varepsilon_{y y}$ plot shows accumulated plasticity near the crack tip region. The strain level is relatively low since the plot is from the early stages of the fatigue loading. The model is not able to capture the crack plasticity wake since the crack is imposed at a certain stage of the sample's fatigue life and not grown.

The normal stress component $\sigma_{y y}$ plot is shown for completeness. This quantity cannot be evaluated with DIC so a direct comparison with experimental data is not feasible. Finally, it is noted that the model is 3D and therefore out-of-plane strain and stress components can be resolved.

\subsection{Validation of the cyclic plasticity model}

In this section a comparison between the experimental and modeling approaches is attempted to validate the cyclic plasticity model. To this aim, both experimental and computational results from the second sample are presented and discussed. In Fig. 10 contour plots of the displacement field $u_{y}$ are given at different fatigue cycles. Fig. 10a corresponds to 1000 cycles while Fig. 10b to 6,000 cycles. On the left side of the figures, results from the computational model are provided and on the right the DIC data are visualized. The FEM coordinate system has been changed to represent the actual experiment, that is, the bottom pin being pulled downwards. Two path lines across the $x$-axis can be observed, which were used for data extraction. Again, the crack size at any stage was dictated by the DIC analysis and implemented in the computational model. Based on the results 
in Fig. 10, it can be concluded that the numerical solution is in good agreement with the experimental data. Hence, at 6,000 cycles the displacement magnitude is augmented as expected.

A similar plot for the total strain $\varepsilon_{y y}$ field is given in Fig. 11. The strain field is well resolved around the crack tip in the numerical solution whereas some noise is observed in the DIC measurements. This is attributed to the lower strain limit which was set equal to $0 \%$ in these plots. As it was stated earlier, the crack tip plastic wake is not captured by the model since the crack is not grown in the numerical solution.

In order to validate the simulation results using the DIC measurements, two paths were defined to extract displacement gradients on the top and the bottom side of the crack tip. For 1000 cycles, the two paths are located $\sim 0.27 \mathrm{~mm}(10.6$ mils) apart and parallel with the crack surface. The path origin is the crack tip and therefore the total length is $1.85 \mathrm{~mm}$ (73 mils). For 6,000 cycles the paths distance is $\sim 0.27 \mathrm{~mm}$ (13 mils) and their total length $4.37 \mathrm{~mm}$ (172 mils).

Fig. 12a shows the experimentally measured and numerically evaluated relative displacements between the two paths at 1000 and 6,000 cycles. The horizontal axis measures the distance from the crack tip towards the notch. It is noticed that at $x=0$, the relative displacement is nonzero since the paths are placed at a certain distance from the crack surface. The displacement evolution at the crack tip location between the two stages of fatigue life is derived from the DIC data equal to $1.19 \mathrm{~mm}(47 \mathrm{mils})$. The trend of the opening displacement is nonlinear in the whole range. The slope of the measured and the predicted values are similar except for the areas that the DIC values diverge. 
At the plot that corresponds to 1000 cycles, the elastic solution was added (black line) to (i) emphasize that an elastoplastic model is needed to describe the near crack tip field, and (ii) verify that the two paths selected are indeed in the plastic zone. Typically, for paths located away from the crack location, the localized plasticity does not affect the displacements and even a simple elastic solution produces the displacements. As further distances from the crack tip, the two numerical solutions converge, that is, the elastic solution will be recovered by the elastoplastic model. However, the waviness in the DIC solution reveals the need for more resolution. The absolute error between the two approaches, defined as $\delta u_{y}=\left|\Delta u_{y}^{F E M}-\Delta u_{y}^{D I C}\right|$, is plotted in Fig. 11c. It is observed that the error is generally below $5.08 \mu \mathrm{m}$ (0.2 mils) at 1000 cycles and $10.16 \mu \mathrm{m}$ (0.4 mils) at 6,000 cycles. Also, a more accurate solution could be achieved by a better calibration of the constitutive model parameters.

Next, the total strain $\varepsilon_{y y}$ is extracted as an alternative way to validate the numerical predictions. The path lines used for the data extraction start at the crack tip and extend towards the crack growth direction. The distance between the two paths is $\sim 0.26 \mathrm{~mm}(10.2)$ mils and their length is $6.38 \mathrm{~mm}$ (251 mils) and $3.91 \mathrm{~mm}$ (154 mils) for 1000 and 6,000 cycles, respectively. The comparison between the two approaches is given in Fig. 12b again for 1000 and 6,000 cycles. The strain at the crack tip is increased by $1 \%$ between these two stages as shown in the DIC data. At that region, some mismatch between the experimental data and the numerical prediction is observed. This discrepancy could be attributed to the constitutive model used to capture the cyclic plasticity as well as the scatter associated with material response. Away from the crack tip, the two datasets 
match indicating that the model captures the elastic field correctly. The variability in post yield material response can introduce additional mismatch between prediction and measured crack tip plasticity. The numerical results were found to be closer to the DIC data for the 6,000 cycles comparison, however, a discrepancy was observed in the strain increase near the crack tip region compared with the 1,000 cycles dataset. This behavior is depicted in the absolute error plot, where

the error $\delta \varepsilon_{y y}=\left|\Delta \varepsilon_{y y}^{F E M}-\Delta \varepsilon_{y y}^{D I C}\right|$, is shown in Fig. 12c. It should be reminded that the strain field is not directly measured in DIC but calculated from the measured displacements and hence it dependents on interpolation which potentially introduces additional errors.

\section{Concluding remarks}

In this article an integrated experimental-computational approach to simulate Mode I low cycle fatigue crack growth in Ni-based superalloy compact tension specimens was presented. The fatigue damage evolution was monitored by Digital Image Correlation providing datasets to validate a confined crack tip plasticity model. The model was calibrated using post yield stress-strain measurements from round bar specimens and implemented in a 3D Finite Element code. The approach considered stationary cracks whose length was identified by DIC at different fatigue life stages and therefore the model used was not computationally demanding while the obtained results showed good agreement with the experimental data. Overall, the presented approach attempts to validate an approach to quantitatively describe plasticity effects near a growing crack and demonstrates a way to utilize rich measurement datasets obtained by full field methods in developing analytical and computational modeling related to fatigue. 


\section{Acknowledgments}

The authors greatly acknowledge the members of the Theoretical \& Applied Mechanics Group at

Drexel University for the assistance in obtaining all experimental results presented in this article.

In addition, part of the analysis of the Digital Image Correlation results was performed under the auspices of the U.S. Department of Energy by Lawrence Livermore National Laboratory under contract DE-AC52-07NA27344. Finally, the authors gratefully acknowledge the support from Tim Hanlon, GE GRC, for guidance in designing the fatigue crack growth testing plan, as well as to Andy Powell, GE Aviation, for providing the material used to conduct the experimental portion of this research.

\section{References}

1. Kamaya, M., (2008). Growth evaluation of multiple interacting surface cracks. Part II: Growth evaluation of parallel cracks. Engineering Fracture Mechanics. 75(6): p. 1350-1366.

2. Carstensen, J.V. and T. Magnin, (2001). Characterisation and quantification of multiple crack growth during low cycle fatigue. International Journal of Fatigue. 23, Supplement 1: p. 195-200.

3. Chan, K.S., (2010). Roles of microstructure in fatigue crack initiation. International Journal of Fatigue. 32(9): p. 1428-1447.

4. Hasegawa, S., Y. Tsuchida, H. Yano, and M. Matsui, (2007). Evaluation of low cycle fatigue life in AZ31 magnesium alloy. International Journal of Fatigue. 29(9-11): p. 1839-1845.

5. Lv, F., F. Yang, Q.Q. Duan, T.J. Luo, Y.S. Yang, S.X. Li, and Z.F. Zhang, (2009). Tensile and low-cycle fatigue properties of $\mathrm{Mg}-2.8 \% \mathrm{Al}-1.1 \% \mathrm{Zn}-0.4 \% \mathrm{Mn}$ alloy along the transverse and rolling directions. Scr. Mater. 61(9): p. 887-890. 
6. Matsuzuki, M. and S. Horibe, (2009). Analysis of fatigue damage process in magnesium alloy AZ31. Materials Science and Engineering: A. 504(1-2): p. 169-174.

7. Begum, S., D.L. Chen, S. Xu, and A.A. Luo, (2009). Low cycle fatigue properties of an extruded AZ31 magnesium alloy. International Journal of Fatigue. 31(4): p. 726-735.

8. Ishihara, S., Z. Nan, and T. Goshima, (2007). Effect of microstructure on fatigue behavior of AZ31 magnesium alloy. Materials Science and Engineering: A. 468-470: p. 214-222.

9. Koike, J., N. Fujiyama, D. Ando, and Y. Sutou, (2010). Roles of deformation twinning and dislocation slip in the fatigue failure mechanism of AZ31 Mg alloys. Scr. Mater. 63(7): p. $747-750$.

10. Yang, F., S.M. Yin, S.X. Li, and Z.F. Zhang, (2008). Crack initiation mechanism of extruded AZ31 magnesium alloy in the very high cycle fatigue regime. Materials Science and Engineering: A. 491(1-2): p. 131-136.

11. Yin, S.M., H.J. Yang, S.X. Li, S.D. Wu, and F. Yang, (2008). Cyclic deformation behavior of as-extruded Mg-3\%Al-1\%Zn. Scr. Mater. 58(9): p. 751-754.

12. Wu, L., S.R. Agnew, D.W. Brown, G.M. Stoica, B. Clausen, A. Jain, D.E. Fielden, and P.K. Liaw, (2008). Internal stress relaxation and load redistribution during the twinningdetwinning-dominated cyclic deformation of a wrought magnesium alloy, ZK60A. Acta Materialia. 56(14): p. 3699-3707.

13. Wu, L., S.R. Agnew, Y. Ren, D.W. Brown, B. Clausen, G.M. Stoica, H.R. Wenk, and P.K. Liaw, (2010). The effects of texture and extension twinning on the low-cycle fatigue behavior of a rolled magnesium alloy, AZ31B. Materials Science and Engineering: A. 527(26): p. 7057-7067.

14. Wu, L., A. Jain, D.W. Brown, G.M. Stoica, S.R. Agnew, B. Clausen, D.E. Fielden, and P.K. Liaw, (2008). Twinning-detwinning behavior during the strain-controlled low-cycle fatigue testing of a wrought magnesium alloy, ZK60A. Acta Materialia. 56(4): p. 688-695.

15. Schuren, J.C., M.P. Miller, and A. Kazimirov, (2012). A Mechanical Testing Capability for Measuring the Microscale Deformation Behavior of Structural Materials. Experimental Mechanics. 52(5): p. 461-479. 
16. Lamark, T.T., F. Chmelík, Y. Estrin, and P. Lukáč, (2004). Cyclic deformation of a magnesium alloy investigated by the acoustic emission technique. J. Alloys Compd. 378(12): p. 202-206.

17. Lou, X.Y., M. Li, R.K. Boger, S.R. Agnew, and R.H. Wagoner, (2007). Hardening evolution of AZ31B Mg sheet. International Journal of Plasticity. 23(1): p. 44-86.

18. Muránsky, O., M.R. Barnett, D.G. Carr, S.C. Vogel, and E.C. Oliver, (2010). Investigation of deformation twinning in a fine-grained and coarse-grained ZM20 Mg alloy: Combined in situ neutron diffraction and acoustic emission. Acta Materialia. 58(5): p. 1503-1517.

19. Dunne, F.P.E., A.J. Wilkinson, and R. Allen, (2007). Experimental and computational studies of low cycle fatigue crack nucleation in a polycrystal. International Journal of Plasticity. 23(2): p. 273-295.

20. Niendorf, T., J. Dadda, D. Canadinc, H.J. Maier, and I. Karaman, (2009). Monitoring the fatigue-induced damage evolution in ultrafine-grained interstitial-free steel utilizing digital image correlation. Materials Science and Engineering: A. 517(1-2): p. 225-234.

21. Boehlert, C.J., C.J. Cowen, S. Tamirisakandala, D.J. McEldowney, and D.B. Miracle, (2006). In situ scanning electron microscopy observations of tensile deformation in a boronmodified Ti-6Al-4V alloy. Scr. Mater. 55(5): p. 465-468.

22. Fukino, T. and S. Tsurekawa, (2008). $<$ I $>$ In-Situ $</$ I $>$ SEM/EBSD Observation of \&alpha;\&frasl;\&gamma; Phase Transformation in Fe-Ni Alloy. MATERIALS TRANSACTIONS. 49(12): p. 2770-2775.

23. El Bartali, A., V. Aubin, and S. Degallaix, (2009). Surface observation and measurement techniques to study the fatigue damage micromechanisms in a duplex stainless steel. International Journal of Fatigue. 31(11-12): p. 2049-2055.

24. Carroll, J., W. Abuzaid, J. Lambros, and H. Sehitoglu, (2010). An experimental methodology to relate local strain to microstructural texture. Rev. Sci. Instrum. 81(8): p. 083703.

25. Efstathiou, C. and H. Sehitoglu, (2010). Strain hardening and heterogeneous deformation during twinning in Hadfield steel. Acta Materialia. 58(5): p. 1479-1488. 
26. El Bartali, A., P. Evrard, V. Aubin, S. Herenú, I. Alvarez-Armas, A.F. Armas, and S. Degallaix-Moreuil, (2010). Strain heterogeneities between phases in a duplex stainless steel. Comparison between measures and simulation. Procedia Engineering. 2(1): p. 2229-2237.

27. Nowell, D. and P.F.P. de Matos, (2010). Application of digital image correlation to the investigation of crack closure following overloads. Procedia Engineering. 2(1): p. 1035-1043.

28. Vanlanduit, S., J. Vanherzeele, R. Longo, and P. Guillaume, (2009). A digital image correlation method for fatigue test experiments. Optics and Lasers in Engineering. 47(3-4): p. $371-378$.

29. Zhao, Z., M. Ramesh, D. Raabe, A.M. Cuitiño, and R. Radovitzky, (2008). Investigation of three-dimensional aspects of grain-scale plastic surface deformation of an aluminum oligocrystal. International Journal of Plasticity. 24(12): p. 2278-2297.

30. Zhu, G., X. Hu, J. Kang, R.K. Mishra, and D.S. Wilkinson, (2011). Deformation inhomogeneity in large-grained AA5754 sheets. Materials Science and Engineering: A. 528(12): p. 4187-4198.

31. Ha, K. and R.A. Schapery, (1998). A three-dimensional viscoelastic constitutive model for particulate composites with growing damage and its experimental validation. Int. J. Solids Struct. 35(26-27): p. 3497-3517.

32. Moerman, K.M., C.A. Holt, S.L. Evans, and C.K. Simms, (2009). Digital image correlation and finite element modelling as a method to determine mechanical properties of human soft tissue in vivo. Journal of Biomechanics. 42(8): p. 1150-1153.

33. Périé, J.N., H. Leclerc, S. Roux, and F. Hild, (2009). Digital image correlation and biaxial test on composite material for anisotropic damage law identification. Int. J. Solids Struct. 46(11-12): p. 2388-2396.

34. Rechenmacher, A.L. and Z. Medina-Cetina, (2007). Calibration of Soil Constitutive Models with Spatially Varying Parameters. Journal of Geotechnical and Geoenvironmental Engineering. 133(12): p. 1567-1576. 
35. El Bartali, A., V. Aubin, and S. Degallaix, (2008). Fatigue damage analysis in a duplex stainless steel by digital image correlation technique. Fatigue $\&$ Fracture of Engineering Materials \& Structures. 31(2): p. 137-151.

36. Hamam, R., F. Hild, and S. Roux, (2007). Stress Intensity Factor Gauging by Digital Image Correlation: Application in Cyclic Fatigue. Strain. 43(3): p. 181-192.

37. Carroll, J., C. Efstathiou, J. Lambros, H. Sehitoglu, B. Hauber, S. Spottswood, and R. Chona, (2009). Investigation of fatigue crack closure using multiscale image correlation experiments. Engineering Fracture Mechanics. 76(15): p. 2384-2398.

38. Carroll, J.D., W. Abuzaid, J. Lambros, and H. Sehitoglu, (2013). High resolution digital image correlation measurements of strain accumulation in fatigue crack growth. International Journal of Fatigue. 57: p. 140-150.

39. Abuzaid, W., H. Sehitoglu, and J. Lambros, (2013). Plastic strain localization and fatigue micro-crack formation in Hastelloy X. Materials Science and Engineering: A. 561: p. 507519.

40. Mathieu, F., F. Hild, and S. Roux, (2012). Identification of a crack propagation law by digital image correlation. International Journal of Fatigue. 36(1): p. 146-154.

41. Mathieu, F., F. Hild, and S. Roux, (2013). Image-based identification procedure of a crack propagation law. Engineering Fracture Mechanics. 103(0): p. 48-59.

42. McClung, R.C. and H. Sehitoglu, (1989). On the finite element analysis of fatigue crack closure-1. Basic modeling issues. Engineering Fracture Mechanics. 33(2): p. 237-252.

43. McClung, R.C. and H. Sehitoglu, (1989). On the finite element analysis of fatigue crack closure -2. Numerical results. Engineering Fracture Mechanics. 33(2): p. 253-272.

44. de Matos, P.F.P. and D. Nowell, (2008). Numerical simulation of plasticity-induced fatigue crack closure with emphasis on the crack growth scheme: 2D and 3D analyses. Engineering Fracture Mechanics. 75(8): p. 2087-2114.

45. Jiang, Y. and M. Feng, (2004). Modeling of Fatigue Crack Propagation. J. Eng. Mater. Technol. 126(1): p. 77-86. 
46. Zhao, L.G., J. Tong, and J. Byrne, (2004). The evolution of the stress-strain fields near a fatigue crack tip and plasticity-induced crack closure revisited. Fatigue $\mathscr{E}$ Fracture of Engineering Materials \& Structures. 27(1): p. 19-29.

47. Shi, J., D. Chopp, J. Lua, N. Sukumar, and T. Belytschko, (2010). Abaqus implementation of extended finite element method using a level set representation for three-dimensional fatigue crack growth and life predictions. Engineering Fracture Mechanics. 77(14): p. 28402863.

48. Sukumar, N., D.L. Chopp, and B. Moran, (2003). Extended finite element method and fast marching method for three-dimensional fatigue crack propagation. Engineering Fracture Mechanics. 70(1): p. 29-48.

49. Périé, J.-N., S. Calloch, C. Cluzel, and F. Hild, (2002). Analysis of a multiaxial test on a $\mathrm{C} / \mathrm{C}$ composite by using digital image correlation and a damage model. Experimental Mechanics. 42(3): p. 318-328.

50. Lim, H., J.D. Carroll, C.C. Battaile, B.L. Boyce, and C.R. Weinberger, (2015). Quantitative comparison between experimental measurements and CP-FEM predictions of plastic deformation in a tantalum oligocrystal. International Journal of Mechanical Sciences. 92: p. $98-108$.

51. Lim, H., J.D. Carroll, C.C. Battaile, T.E. Buchheit, B.L. Boyce, and C.R. Weinberger, (2014). Grain-scale experimental validation of crystal plasticity finite element simulations of tantalum oligocrystals. International Journal of Plasticity. 60: p. 1-18.

52. de Matos, P.F.P. and D. Nowell, (2009). Experimental and numerical investigation of thickness effects in plasticity-induced fatigue crack closure. International Journal of Fatigue. 31(11-12): p. 1795-1804.

53. Roux-Langlois, C., A. Gravouil, M.C. Baietto, J. Réthoré, F. Mathieu, F. Hild, and S. Roux, (2015). DIC identification and X-FEM simulation of fatigue crack growth based on the Williams' series. Int. J. Solids Struct. 53(0): p. 38-47.

54. Heaney, J.A., M.L. Lasonde, A.M. Powell, B.J. Bond, and C.M. O'Brien, Development of a New Cast and Wrought Alloy (René 65) for High Temperature Disk Applications, in 8th 
International Symposium on Superalloy 718 and Derivatives. 2014, John Wiley \& Sons, Inc. p. $67-77$.

55. Ismonov, S., A. Loghin, T. Hanlon, and C. Shen, (2015). Application of crack tip plasticity based fatigue model on high temperature alloy HAYNES® $282 @$. International Journal of Fatigue. 70: p. 146-153.

56. Chaboche, J.L., (1989). Constitutive equations for cyclic plasticity and cyclic viscoplasticity. International Journal of Plasticity. 5(3): p. 247-302.

57. Chaboche, J.L., (1991). On some modifications of kinematic hardening to improve the description of ratchetting effects. International Journal of Plasticity. 7(7): p. 661-678.

58. ANSYS, (2013). Release 15.0. Theory Reference. ANSYS, Inc., Canonsburg, PA.

59. Loghin, A., A.C. Kaya, J. LeMonds, U. Ozkan, Y. Potdar, G. Khan, R. McClain, and J. Laflen, Three-dimensional fracture mechanics development for life assessment of components, in ICF12. 2009: Ottawa, Canada.

60. Klass, O., R. Nastasia, M. Beall, A. Loghin, J. Laflen, and J. LeMonds, Robust tools for crack insertion and propagation, in NAFEMS World Congress. 2011: Boston, MA. 


\section{Figure Captions}

Fig. 1: (a) CT specimen dimensions, (b) optic experimental setup (DIC) used to monitor Mode I crack growth, (c) measuring procedure configuration, (d) different gages used.

Fig. 2: Stress-plastic strain data and material model prediction.

Fig. 3: (a) Finite element mesh discretization and crack tip mesh refinement, (b) boundary conditions description, (c) loading assignment.

Fig. 4: (a) Mesh control parameters that can be adjusted by the user to perform a mesh sensitivity study and location of the two paths along which displacements and strains are extracted from, (b) relative displacements $\Delta u_{y}$ and strains $\varepsilon_{y y}$ on the crack faces for the four meshes considered in the mesh sensitivity study.

Fig. 5: (a) Front and back view of the damaged specimen, detailed front (b) and back (c) view of the crack growth.

Fig. 6: (a) Displacement field evolution with loading cycles, (b) displacement profile as a function of distance from the crack tip, (c) crack opening displacement at various loading cycles. 
Fig. 7: (a) DIC results for strain fields as a function of loading cycles, (b) evolution of strain at the crack tip with number of loading cycles, (c) strain profile as a function of distance from the crack tip at different loading stages.

Fig. 8: (a) Strain profile as a function of distance from the crack tip, (b) strain field evolution with loading cycles.

Fig. 9: Contour plots at 1000 cycles for the displacement field $u_{y}$, total strain $\varepsilon_{y y}$ and stress $\sigma_{y y}$ at max load.

Fig. 10: Comparison of model prediction (left) and DIC data (right) for the displacement field $\left(u_{y}\right)$ for (a) 1000 and (b) 6,000 cycles.

Fig. 11: Comparison of model prediction (left) and DIC data (right) for the total strain field $\left(\varepsilon_{y y}\right)$ for (a) 1000 and (b) 6,000 cycles.

Fig. 12: (a) Comparison of elastic model, elastic-plastic model prediction and DIC data for the relative displacement $\Delta u_{y}$ along the loading direction on 1000 cycles (left) and 6,000 cycles (right). (b) Comparison of elastic model, elastic-plastic model prediction and DIC data for the total strain profile $\varepsilon_{y y}$ along the loading direction on 1000 cycles (left) and 6,000 cycles (right). (c) Absolute error calculation for the displacement (top) and strain fields (bottom). 
(a)

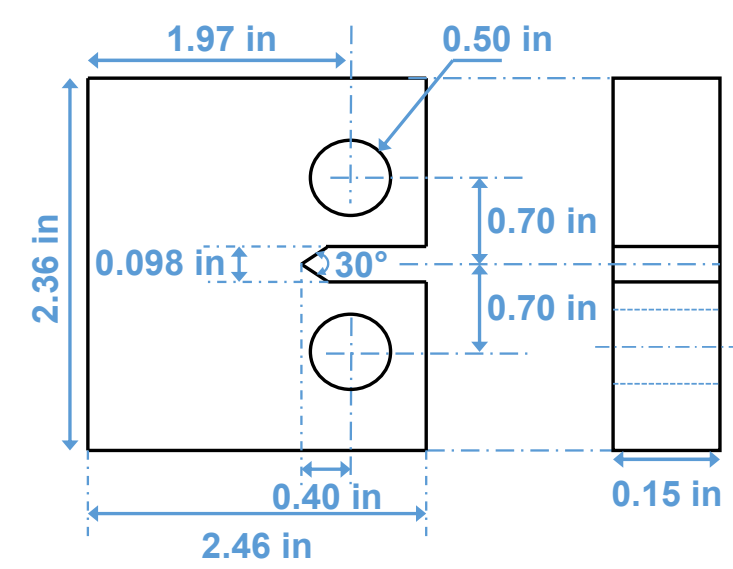

(c)

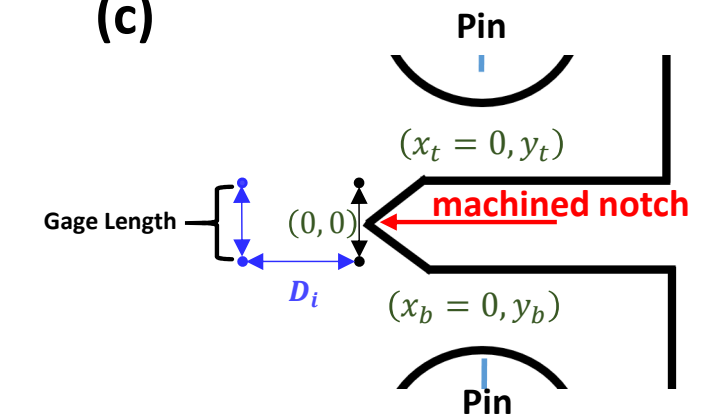

coordinates in mils (b)

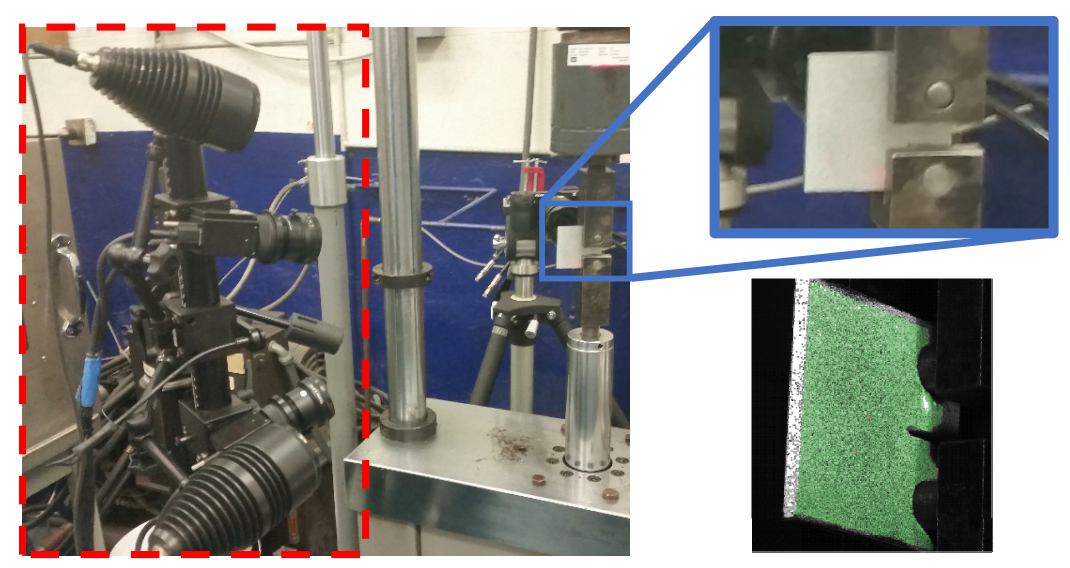

(d)

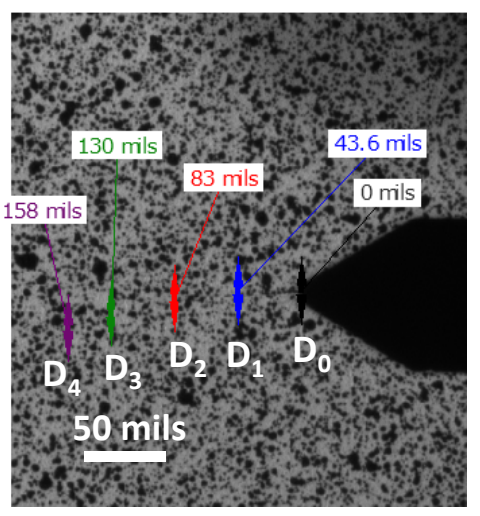




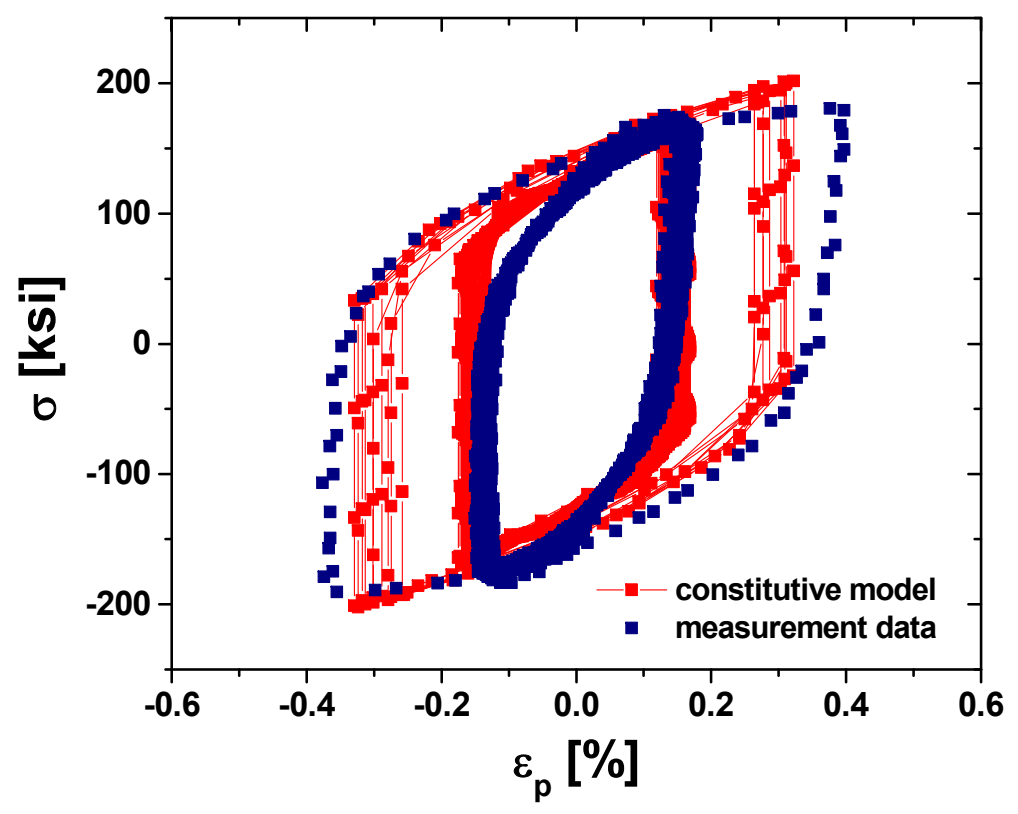


(a)

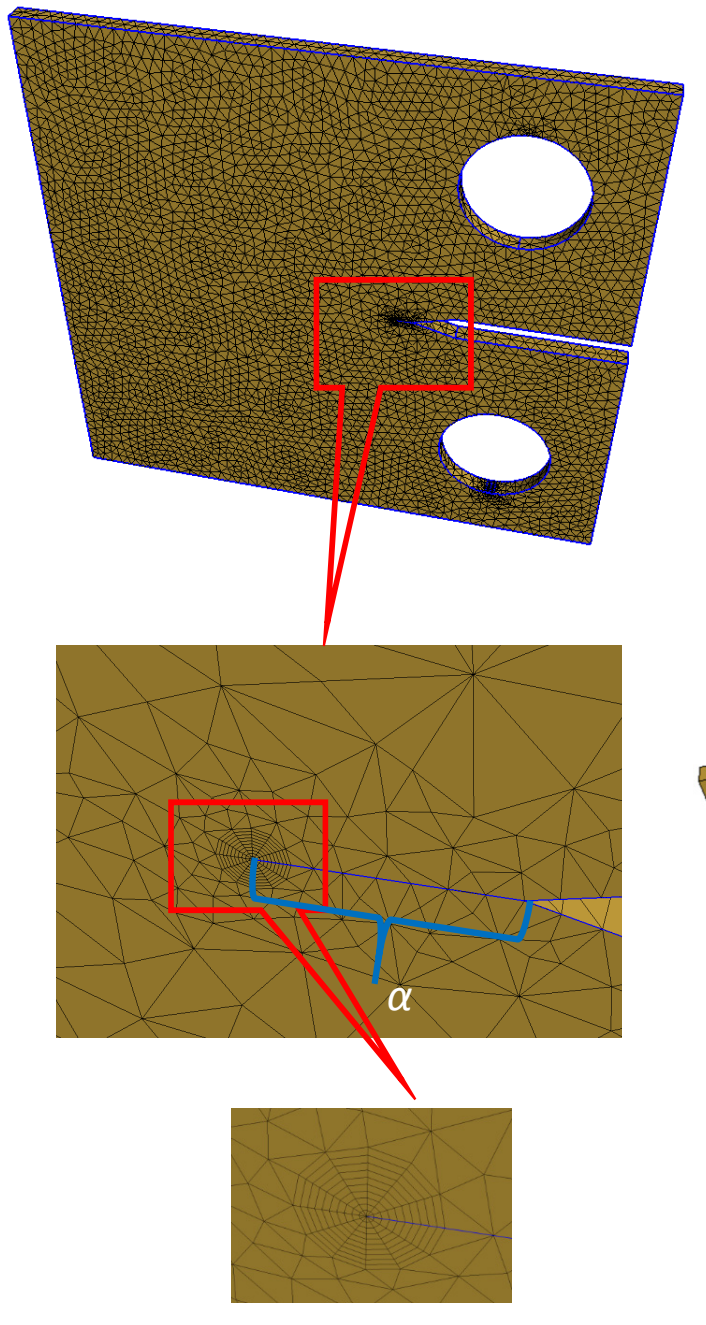

(b)

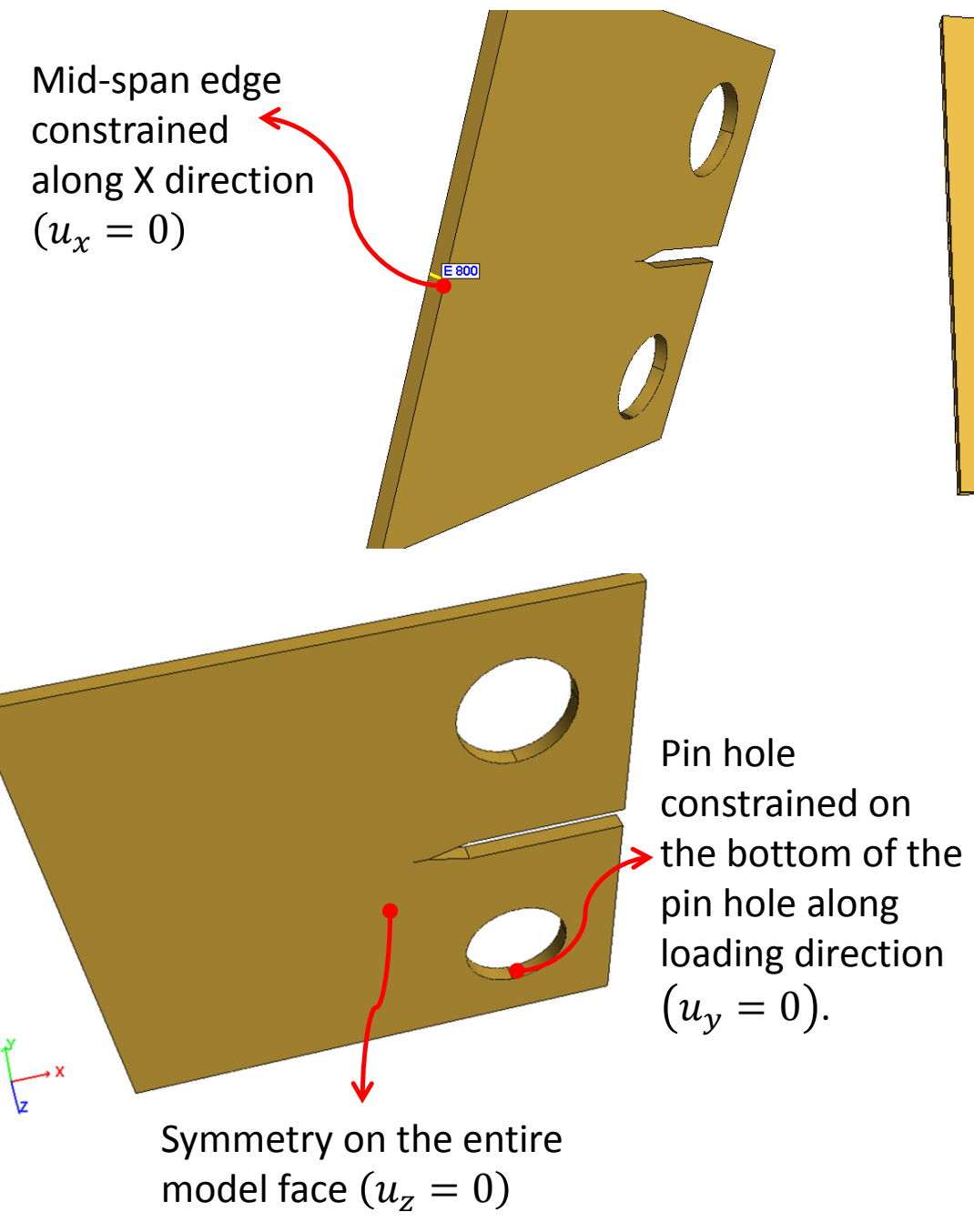

(c)
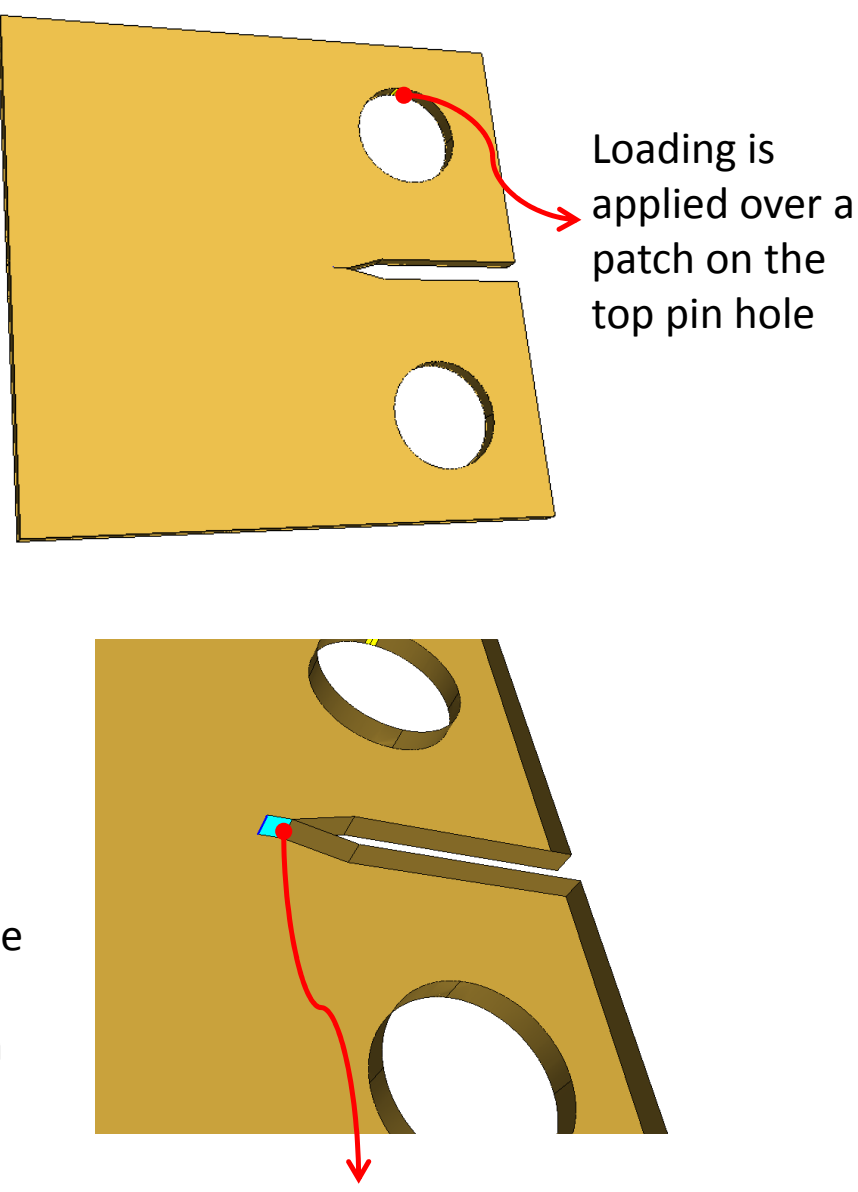

Contact is set on the crack faces since the loading cycle is 0-max 
(a)
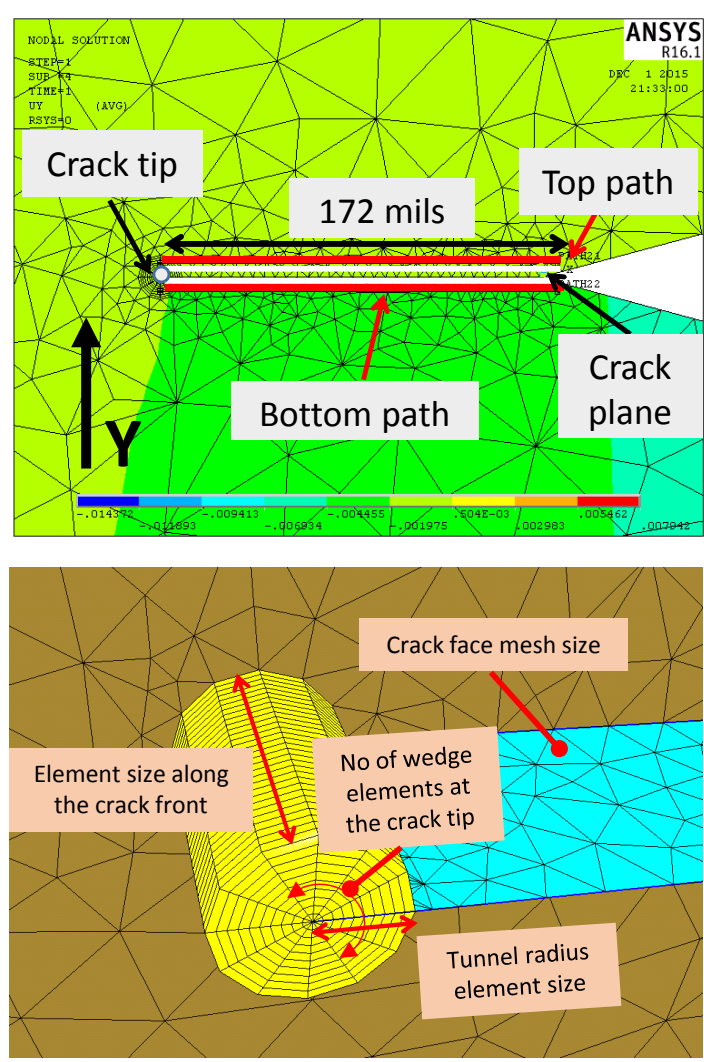

(b)
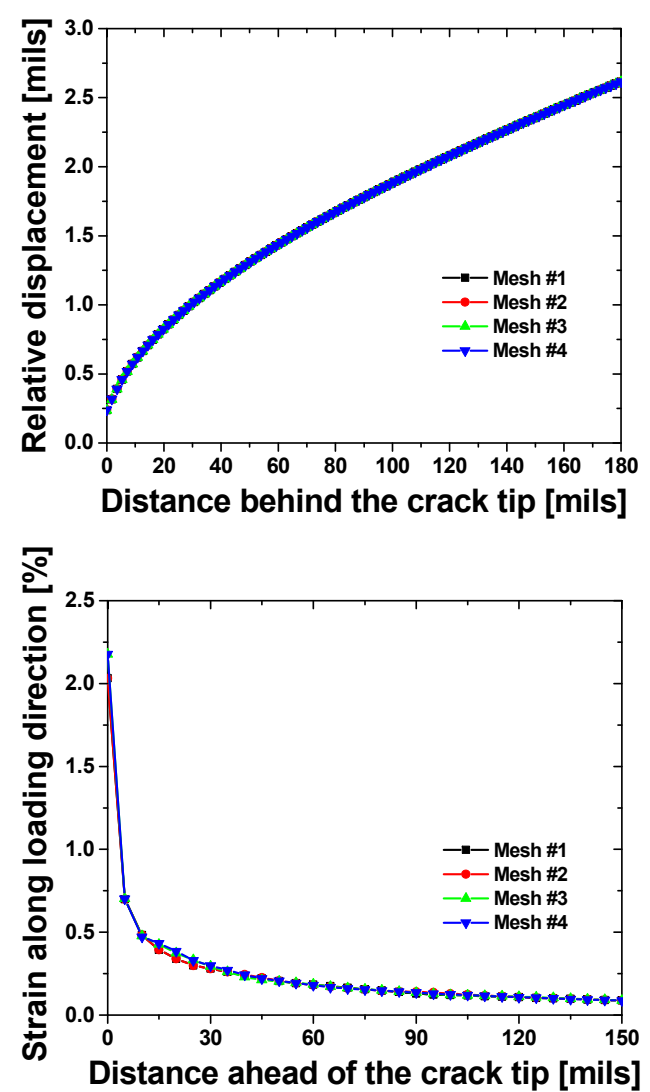
(a)

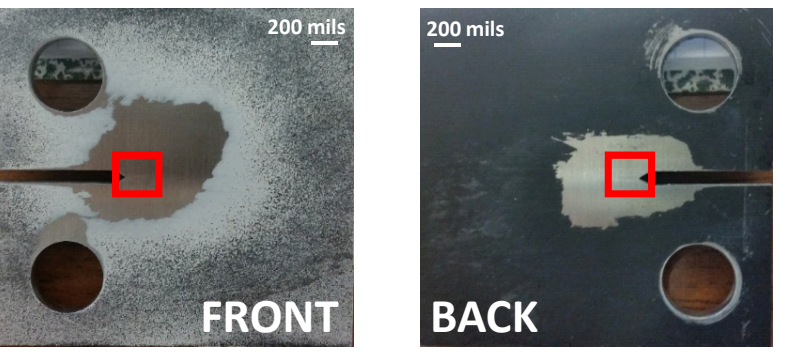

(b)

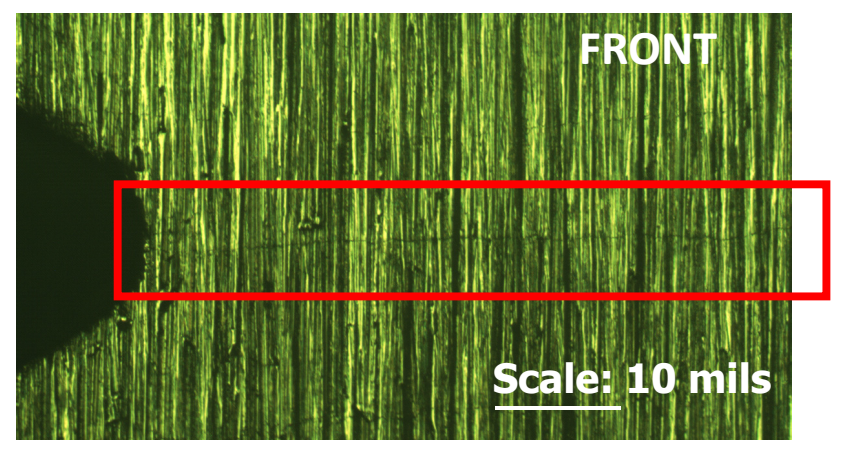

(c) VIr B

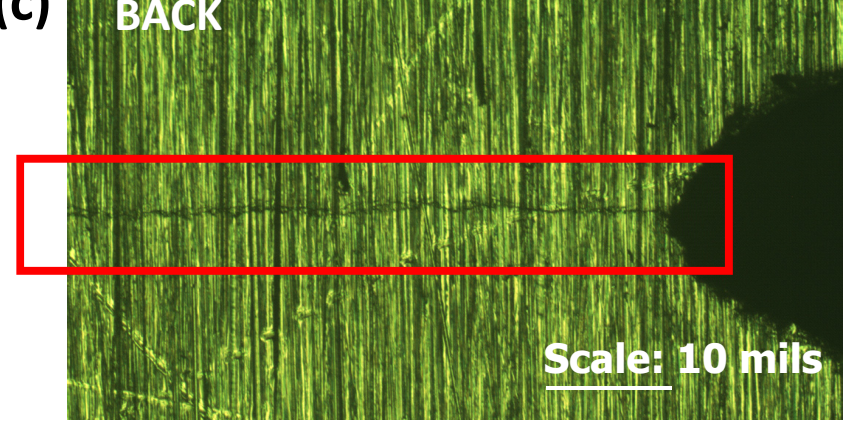


(a)

200 cycles

6500 cycles

10000 cycles
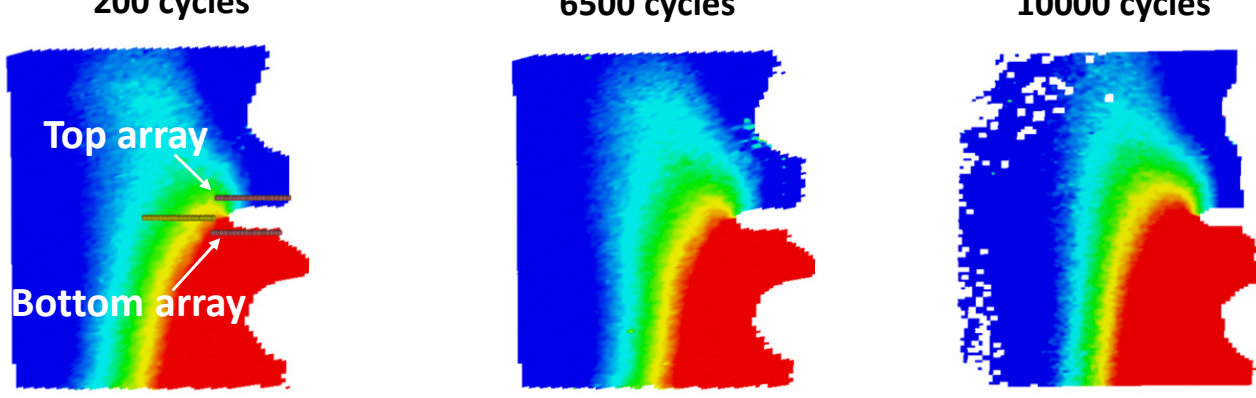

[mil]

0.50

0.45

0.40

0.35

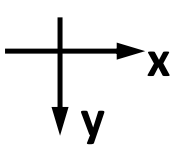

(b)
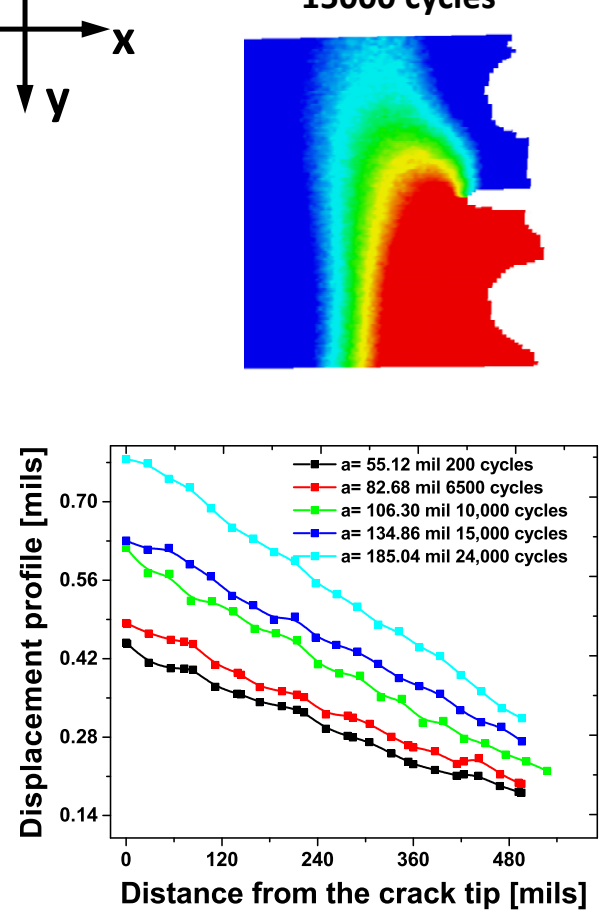

24000 cycles

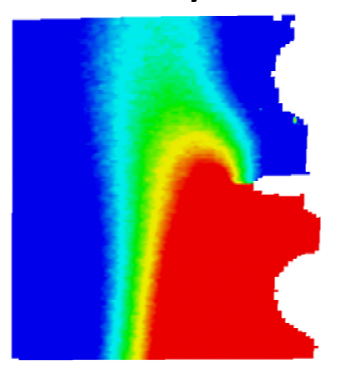

0.30

0.25

0.20

0.15

0.10

0.05

(c)

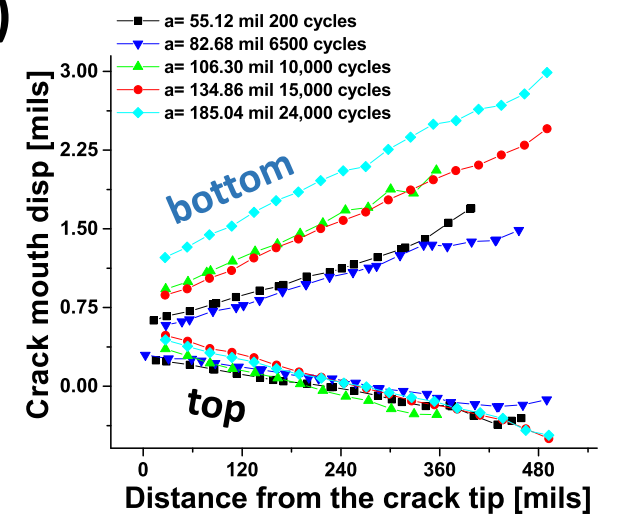


(a)

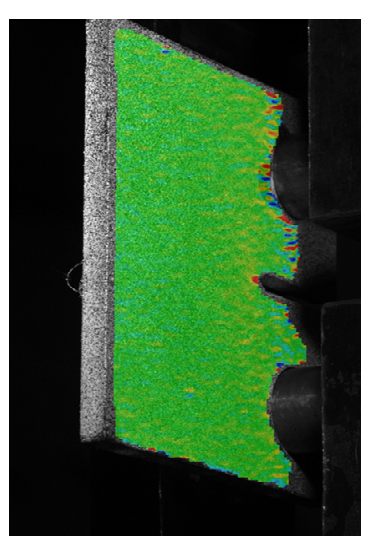

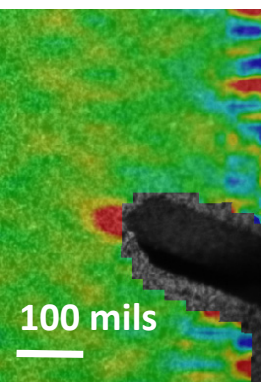

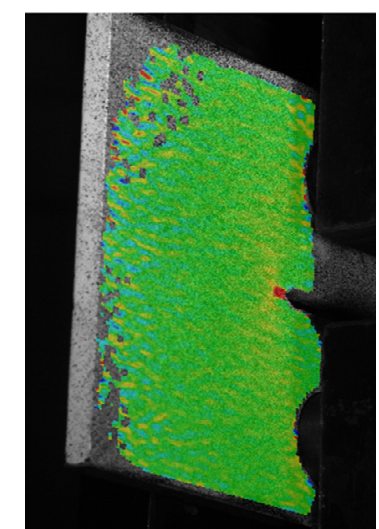

13000 cycles

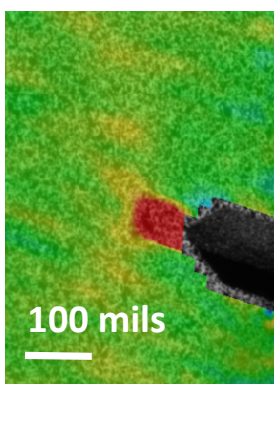

24358 cycles
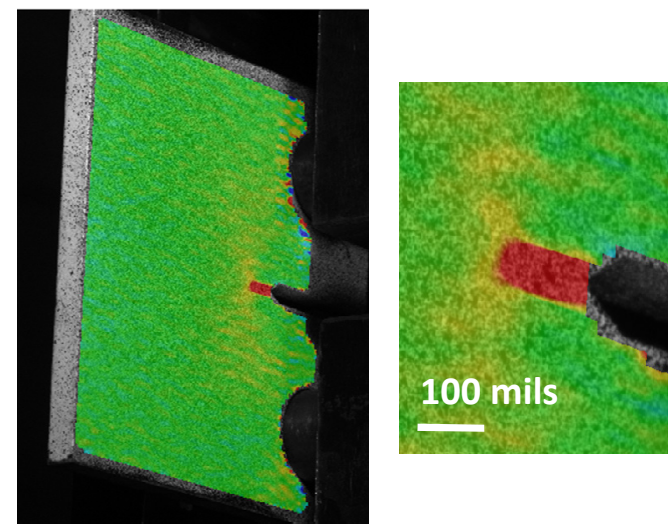

(c)

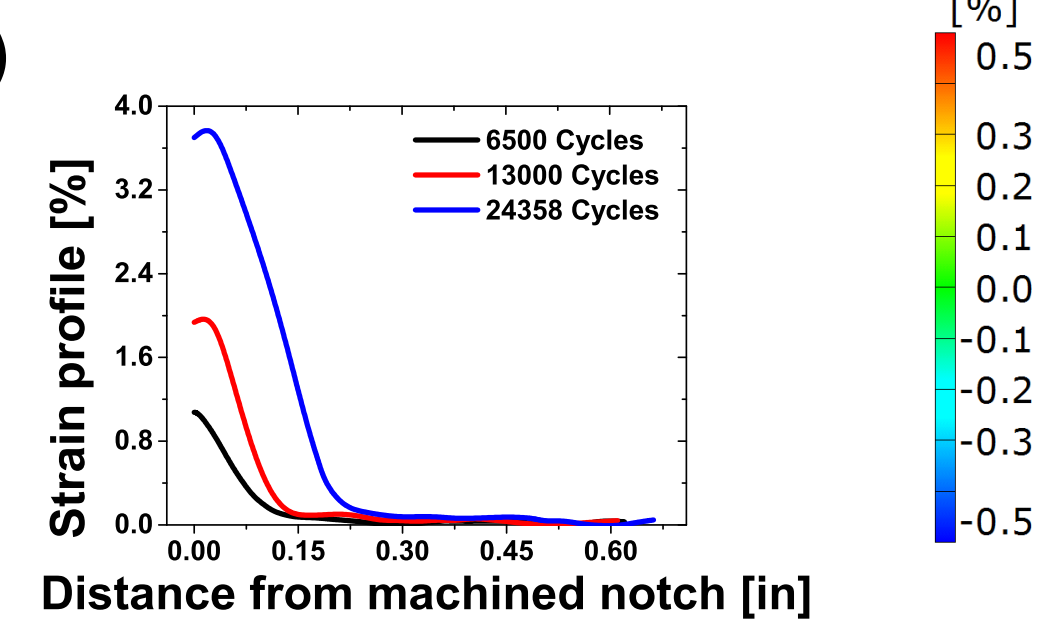

Distance from machined notch [in] (b)

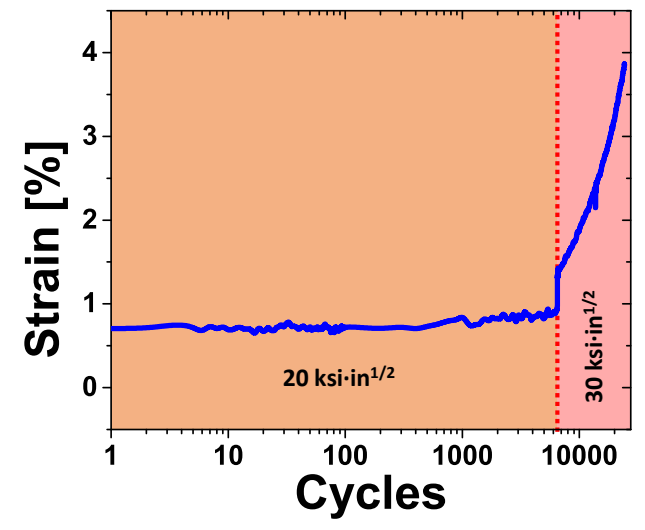


(b)
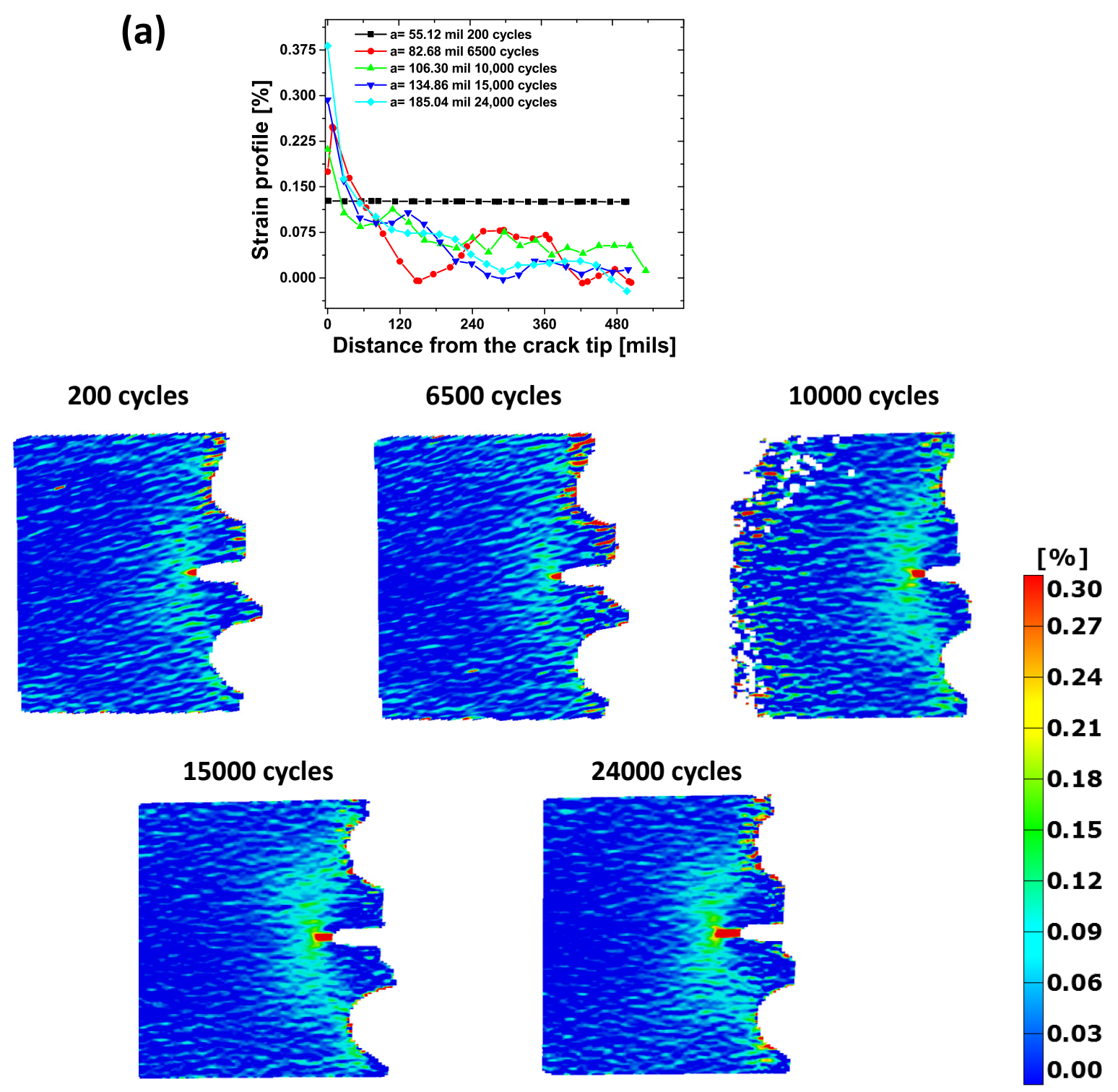

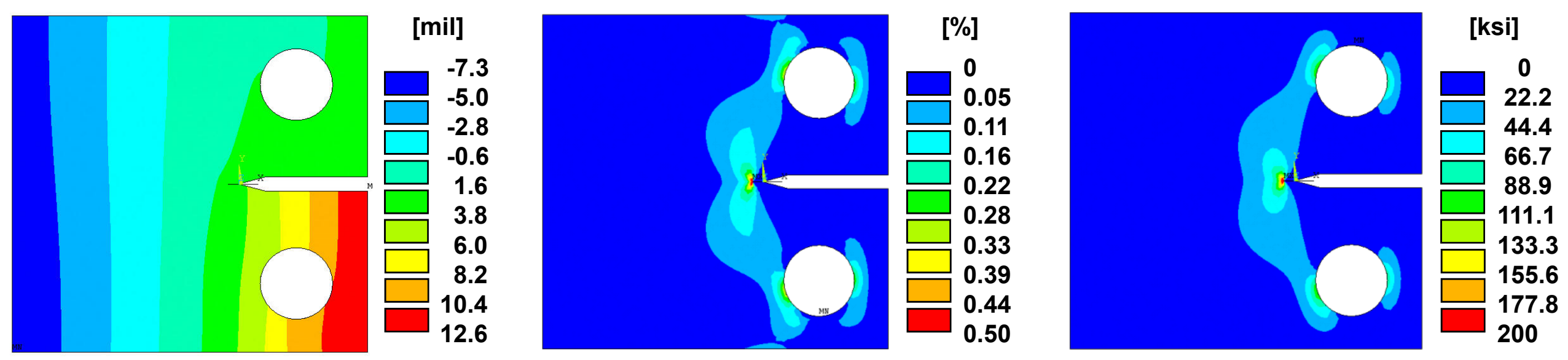
(a)

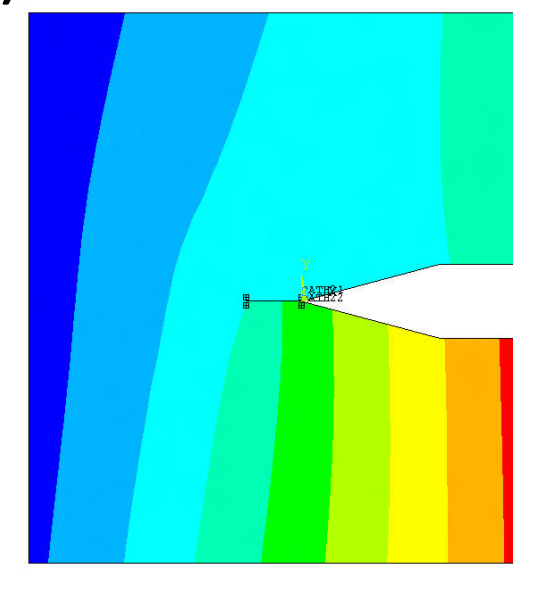

[mil]

\begin{tabular}{|l}
0 \\
$\square$ \\
\hline
\end{tabular}

\begin{tabular}{|l}
\hline \\
$\square$ \\
$\square$ \\
$\square$
\end{tabular}

2.8

(b)
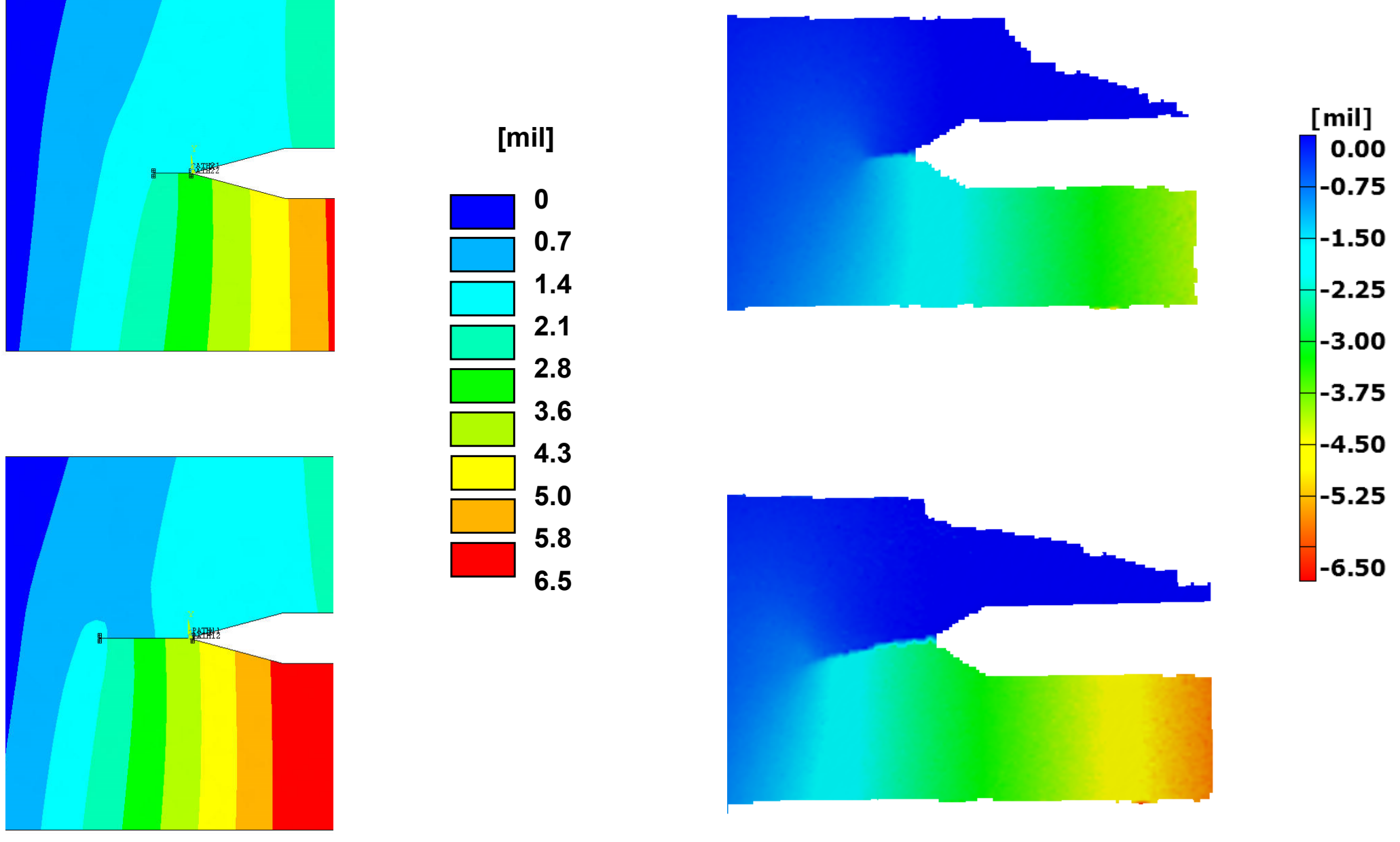
(a)

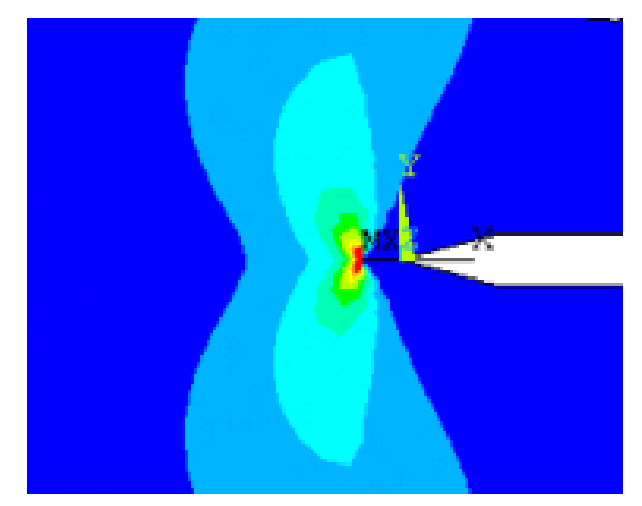

[\%]

\begin{tabular}{|l|l|}
\hline & 0 \\
\hline & 0.05 \\
\hline & 0.11 \\
\hline & 0.16 \\
\hline & 0.22 \\
\hline$\square$ & 0.28 \\
\hline & 0.33 \\
\hline & 0.39 \\
\hline & 0.44 \\
\hline & 0.50
\end{tabular}

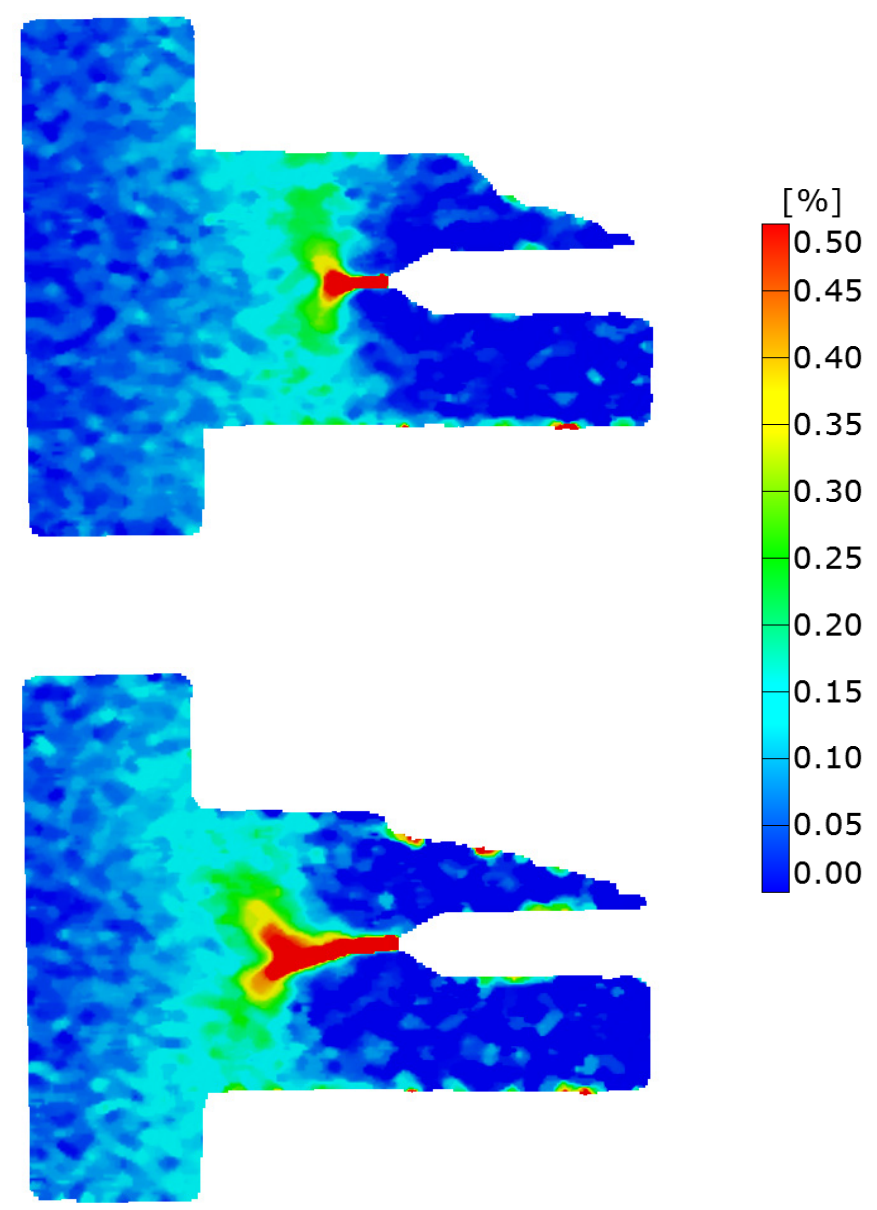

(b)
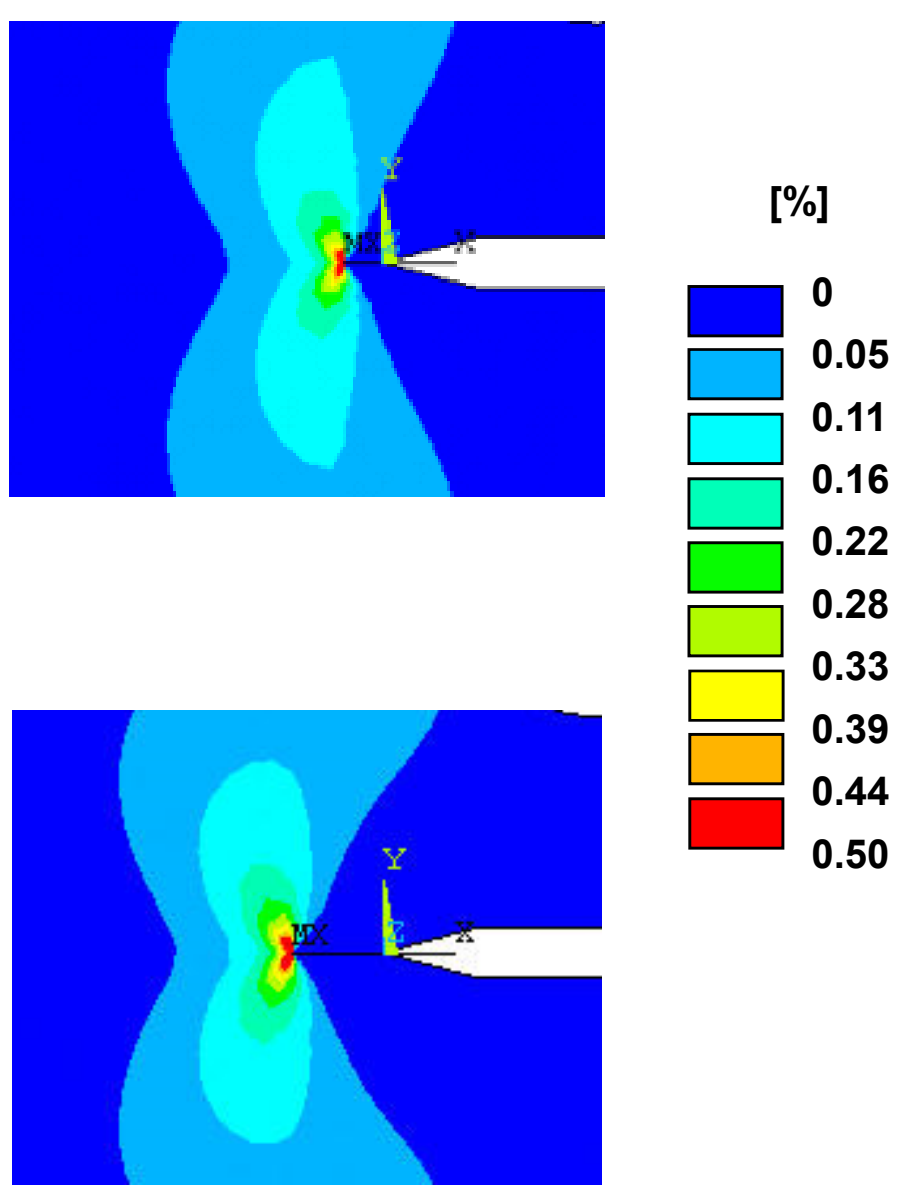
(a)

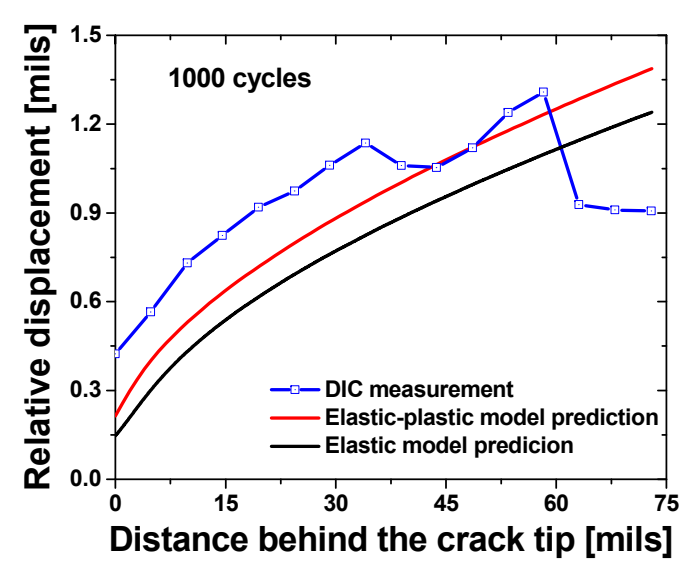

(b)

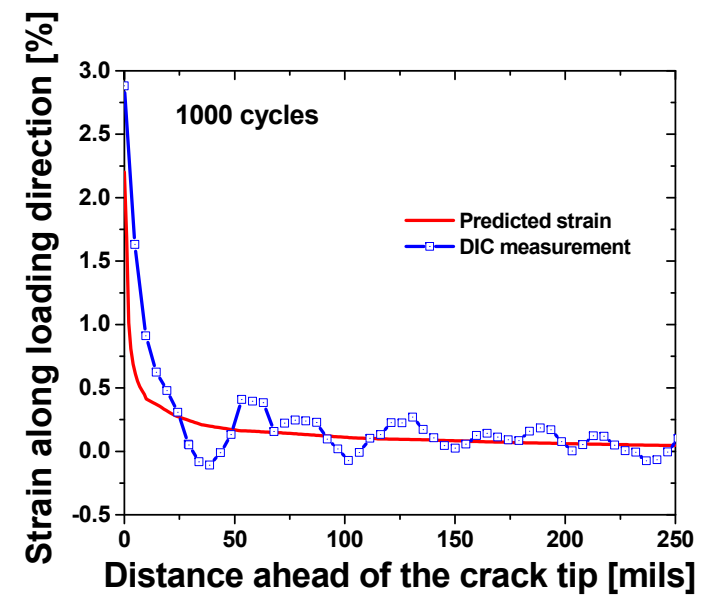

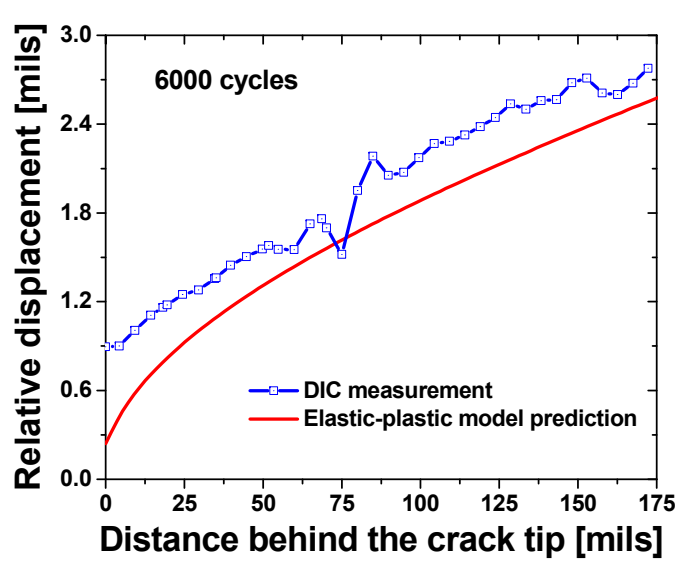

(c)
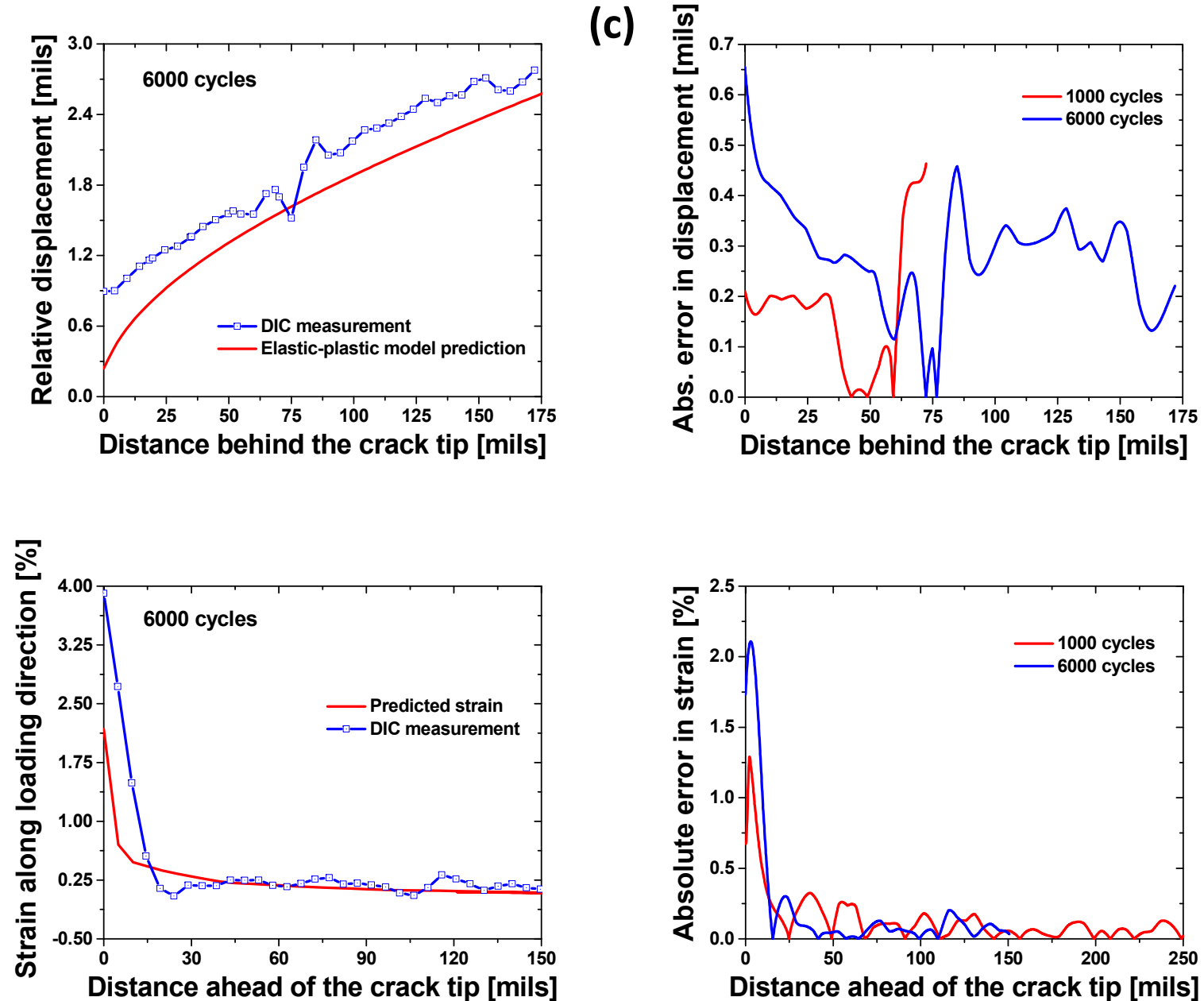

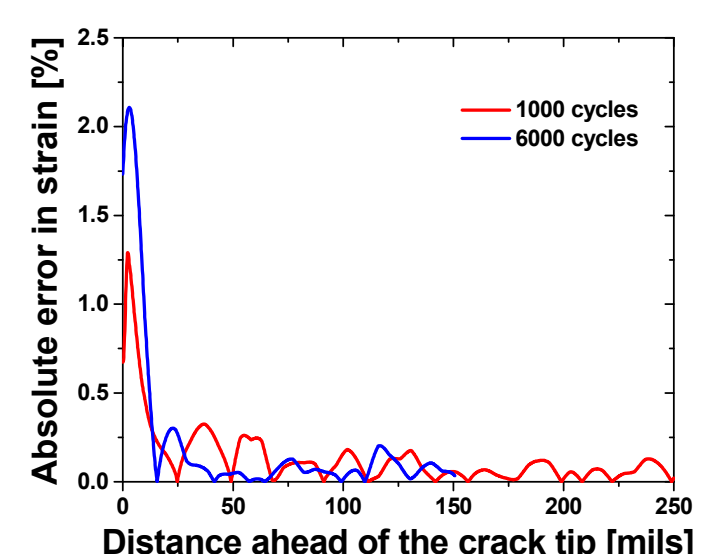


Table 1: DIC gages parameters (Fig. 1d)

\begin{tabular}{ccc}
\hline Gage number & Gage Length [mils] & $\begin{array}{c}\text { Distance from ma- } \\
\text { chined notch [mils] }\end{array}$ \\
\hline 1 & 43.5 & 0 \\
2 & 43.46 & 43.6 \\
3 & 43.5 & 92 \\
4 & 43.43 & 130 \\
5 & 43.43 & 158 \\
\hline
\end{tabular}


Table 2: Chaboche material model parameters

\begin{tabular}{ccccccccccc}
\hline$T$ & $E[\mathrm{ksi}]$ & $\nu$ & $\begin{array}{c}\sigma_{y} \\
{[\mathrm{ksi}]}\end{array}$ & $\begin{array}{c}C_{1} \\
{[\mathrm{ksi}]}\end{array}$ & $\gamma_{1}$ & $\begin{array}{c}C_{2} \\
{[\mathrm{ksi}]}\end{array}$ & $\gamma_{2}$ & $\begin{array}{c}R_{0} \\
{[\mathrm{ksi}]}\end{array}$ & $\begin{array}{c}R_{\infty} \\
{[\mathrm{ksi}]}\end{array}$ & $b$ \\
\hline $70 \mathrm{~F}$ & $3.19 \mathrm{E} 4$ & 0.3 & 121.46 & $6.45 \mathrm{E} 3$ & 69.91 & $2.29 \mathrm{E} 4$ & 264.45 & 1.05 & 5.46 & 2.46 \\
\hline
\end{tabular}

